\title{
Ulnar-sided wrist pain. II. Clinical imaging and treatment
}

\author{
Atsuya Watanabe $\cdot$ Felipe Souza $\cdot$ Peter S. Vezeridis • \\ Philip Blazar • Hiroshi Yoshioka
}

Received: 29 June 2009/Revised: 14 November 2009/Accepted: 17 November 2009/Published online: 10 December 2009

(C) The Author(s) 2009. This article is published with open access at Springerlink.com

\begin{abstract}
Pain at the ulnar aspect of the wrist is a diagnostic challenge for hand surgeons and radiologists due to the small and complex anatomical structures involved. In this article, imaging modalities including radiography, arthrography, ultrasound (US), computed tomography (CT), CT arthrography, magnetic resonance (MR) imaging, and MR arthrography are compared with regard to differential diagnosis. Clinical imaging findings are reviewed for a more comprehensive understanding of this disorder. Treatments for the common diseases that cause the ulnar-sided wrist pain including extensor carpi ulnaris (ECU) tendonitis, flexor carpi ulnaris (FCU) tendonitis, pisotriquetral arthritis, triangular fibrocartilage complex (TFCC) lesions, ulnar impaction, lunotriquetral (LT) instability, and distal radioulnar joint (DRUJ) instability are reviewed.
\end{abstract}

Keywords Wrist pain $\cdot$ Ulnar side $\cdot$ Imaging $\cdot$ Treatment

\author{
A. Watanabe $\cdot$ F. Souza $\cdot$ H. Yoshioka \\ Department of Radiology, Brigham and Women's Hospital, \\ Boston, MA, USA \\ P. S. Vezeridis $\cdot$ P. Blazar \\ Department of Orthopaedic Surgery, \\ Brigham and Women's Hospital, \\ Boston, MA, USA \\ H. Yoshioka \\ Department of Radiological Sciences, \\ University of California-Irvine, \\ Irvine, CA, USA \\ H. Yoshioka $(\bowtie)$ \\ Department of Radiological Sciences, UC Irvine Medical Center, \\ 101 City Drive South, Route 140, \\ Orange, CA 92868, USA \\ e-mail: hiroshi@uci.edu
}

\section{Introduction}

Pain at the ulnar aspect of the wrist is a diagnostic challenge for hand surgeons and radiologists because of the small and complex anatomical structures involved. In this article, imaging modalities for ulnar-sided wrist pain, differential diagnosis, and clinical imaging findings are reviewed for a comprehensive understanding of these disorders. Treatment for the common diseases that cause the ulnar-sided wrist pain were reviewed.

\section{Clinical imaging}

Imaging modalities for ulnar-sided wrist pain

\section{Radiography}

In many clinical settings, imaging begins with radiographs that could reveal abnormalities, such as fractures, inflammatory arthritis, osteoarthritis or a congenital anomaly. Usually, posteroanterior (PA) and lateral views of the wrist are obtained. Images should be obtained with the patient seated, the forearm in a neutral position, the elbow flexed to $90^{\circ}$, and the shoulder abducted to $90^{\circ}$. However, in some cases, additional views allow for a more complete evaluation of the wrist. An oblique view in $30^{\circ}$ of pronation allows evaluation of the dorsal ulnar wrist, while the reverse oblique view $\left(30^{\circ}\right.$ of supination) allows evaluation of the volar ulnar aspect of the wrist and a profile of the pisotriquetral joint. The carpal tunnel view is useful to visualize the hook of hamate and possible pisotriquetral pathology. In this view the wrist is dorsiflexed about $35^{\circ}$, and the X-ray beam moves tangentially to the anterior aspect of the wrist (Fig. 1). For optimal evaluation at the time of injury and subsequent follow-up, 


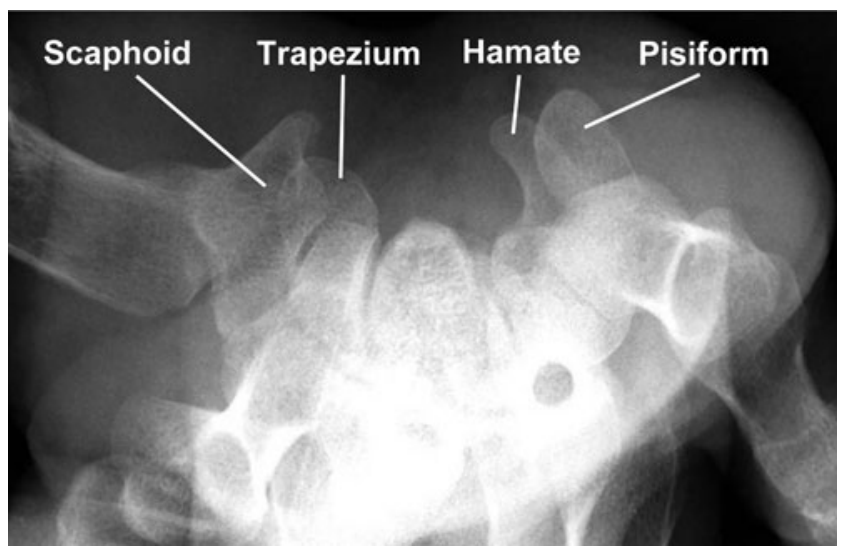

Fig. 1 Carpal tunnel view of the wrist (radiograph). The carpal tunnel is bounded on the ulnar side by the hook of the hamate and on the radial side by the distal end of the scaphoid. The pisiform is ulnar to the hamate and the volar ridge of the trapezium is radial to the scaphoid

standardized positioning and high-quality radiographs must be obtained [1].

\section{Arthrography}

Arthrography had been the favored imaging modality for the evaluation of ruptures of the interosseous ligaments and tears of the triangular fibrocartilage complex (TFCC). For detecting perforations of the TFCC, one of the several causes of ulnar-sided wrist pain, triple-injection arthrography had been considered the "gold" standard [2, 3]. However, several authors have reported that arthrography of the wrist is much less accurate than arthroscopy and has a relatively high rate of false-negative findings [3, 4]. Therefore, during the past several years, arthrography has been largely supplanted by MR imaging for evaluating lesions associated with TFCC.

Depending on the indication and suspicions of the orthopedic surgeon, the technique for arthrography will vary. Contrast material may be injected into one of the three non-communicating spaces of the carpus: the distal radioulnar joint, the radiocarpal joint, and the midcarpal joint. The decision to obtain single-injection arthrography versus triple-injection arthrography must be based on specific clinical findings [5]. One of the most important arthrographic findings is abnormal communication between the carpal rows. However, previous studies have shown that at least one third of cadaver dissections have abnormal communications of the wrist joint. Mikic reported that, with age, the incidence of degenerative perforations that allow these abnormal communications increases [5].

Limitations of the examination are the invasive pain of arthrography, and the potential risks, including irritation and swelling as part of chemical synovitis from possibly a low-osmolar contrast agent. Infection is a very rare complication of arthrography. One study reported that only 45 cases had been encountered in approximately 262,000 arthrograms $(0.017 \%)$ [6].

\section{Ultrasound}

Musculoskeletal ultrasound (US) of the hand and wrist has been increasingly used in clinical practice. Recent rapid technical advances in US, such as new ultra-high frequency probes and smaller probe sizes, have led to improved image quality and accelerated the growth of musculoskeletal US $[2,7]$. While US is generally not helpful in evaluating osseous pathology, it provides valuable information about soft-tissue anatomy [2]. Known advantages of US are its lack of ionizing radiation, noninvasiveness, portability, and low cost. Dynamic and real-time assessment and Doppler imaging are additional benefits of this modality, especially in the imaging of the hand and wrist.

Ultrasound allows for the detection of foreign bodies and the reliable identification of a variety of traumatic lesions affecting tendons, annular pulleys, ligaments, vessels, and nerves as well as inflammatory diseases of tendons, including acute and chronic tenosynovitis and some degenerative conditions in the wrist and hand, such as the ulnar collateral ligament and extensor carpi ulnaris tenosynovitis (Fig. 2) [810]. US can also effectively diagnose tendons that have
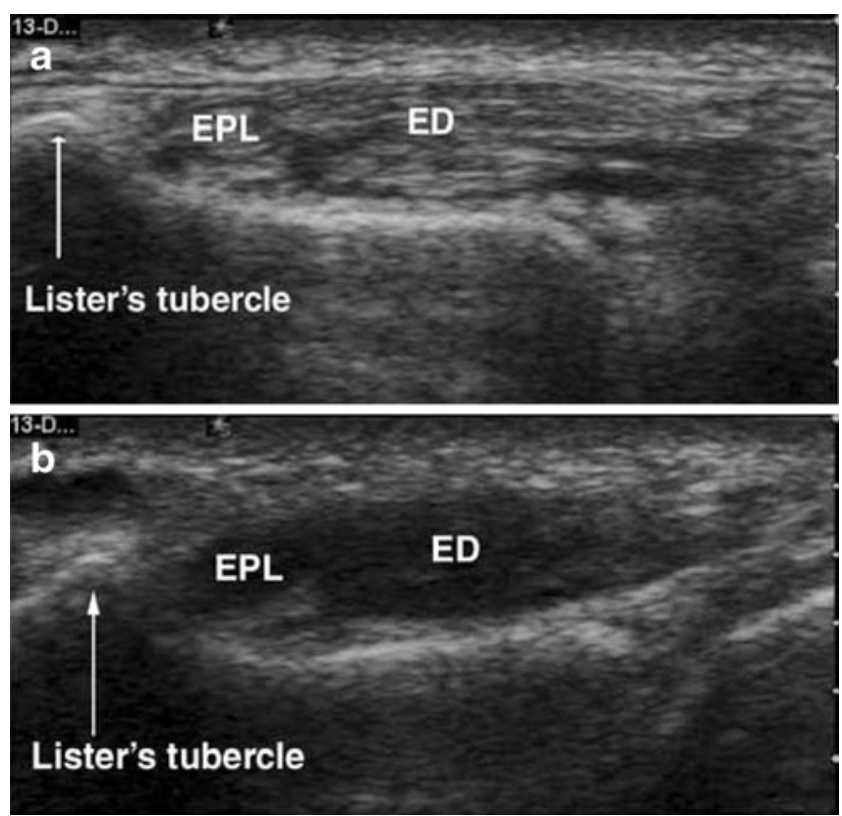

Fig. 2 Transverse ultrasound of the extensor surface of the wrist show the extensor digitorum $(E D)$ and extensor pollicis longus $(E P L)$ tendons, a without artifact on the image obtained with the probe held exactly perpendicular to the tendons, $\mathbf{b}$ but with a significant loss of echogenicity on the image obtained with the probe held at an oblique angle to the tendons. (Reproduced with permission from [151]) 
ruptured by demonstrating tendon non-visualization, blunt torn ends, refractive shadowing, and adjacent fluid. Identification of the retracted proximal tendon facilitates appropriate surgical access and real-time scanning evaluates tendon gliding. [2, 8, 11, 12]. In entrapment neuropathies, US reveals nerve shape changes and possible extrinsic spaceoccupying lesions that may cause nerve compression within the tunnels to allow further characterization of masses (solid vs cystic, vascular vs avascular).

Disadvantages of this method are that it is highly operator-dependent and US images of the triangular TFCC do not provide enough information on its internal structure to allow a final diagnosis [2] and is not helpful for fracture evaluation.

\section{Computed tomography}

One of the main causes for ulnar-sided wrist pain are fractures that can involve the ulnar styloid, pisiform, base of the fifth metacarpal bone as well as the hamate bone. Although conventional radiography remains the primary imaging modality for evaluation of suspected carpal fractures and dislocations, multidetector (MD) CT is playing an increasingly important role. Today, if MR imaging is unavailable, CT examinations are used in addition to conventional studies to further work up unclear wrist pathologies. CT is especially useful in detecting or excluding occult fractures, to document the extent of fractures for staging purposes and to determine subluxation and luxation of the wrist as well as malrotation of the radius and ulna [2]. The advantages of multidetector $\mathrm{CT}$ include a quick and accurate examination with multiplanar (two-dimensional) and volumetric (three-dimensional) reformation [13].

\section{Computed tomographic arthrography}

Because of its low spatial resolution along the Z-axis, use of direct CT arthrography for the evaluation of ulnar-sided wrist pain had, for many years, been limited. However, these limitations have been overcome by the further development of the multi-slice CT system with submillimeter slice thicknesses and high-quality reconstructions in random imaging planes [14]. MDCT arthrography of the wrist can combine the detailed CT display of bony anatomy with a clear image of the ligamentous structures of the wrist [15]. In addition, tears of the TFCC can be differentiated according to their location. For optimal assessment of these structures a tailored contrast material injection technique and multiplanar reformation are recommended [16]. MDCT arthrography, when compared with conventional arthrography, shows more precisely the site of a tear or perforation of the interosseous ligaments of the wrist and the TFCC [17]
Multidetector CT arthrography is limited in its ability to enable the evaluation of soft-tissue abnormalities; therefore, the technique is best used in concert with other imaging techniques such as US or MR imaging [16].

\section{Magnetic resonance imaging}

In $1986 \mathrm{MR}$, imaging of the wrist was first reported in the literature. Subsequent years have seen vast improvements in magnet quality and surface coil manufacture [18]. Today, MR imaging plays an important role in the assessment of the internal derangement of joints and is reported to be an excellent modality for diagnosing hand and wrist disorders [19-22]. While CT provides superior osseous detail, MR imaging has greater sensitivity for soft tissue contrast and subtle bone marrow changes such as bone edema and is, therefore, particularly useful for evaluating occult fractures and stress fractures. However, the use of MR imaging to evaluate the wrist has lagged behind its use in larger joints, such as the knee and hip, because of technical limitations of spatial resolution and the signal-to-noise ratio when imaging the small and intricate structures of the wrist [23]. Thin and contiguous slices are needed for adequate MR imaging of the wrist because even many of the larger ligaments around the wrist are no greater than 1-2 mm thick [22]. Therefore, high-resolution MR imaging is essential to evaluate normal and abnormal features of the hand and wrist [24, 25]. To obtain high-resolution MR imaging of the wrist, high signal-to-noise ratio images are essential. High magnetic field MR imaging such as $3.0 \mathrm{~T}$ is one option in achieving such a ratio (Fig. 3) [26], and recent studies demonstrate improved diagnostic capability and quality of 3.0 T MRI compared with $1.5 \mathrm{~T}$ MRI related to injury to the wrist ligaments (lunotriquetral, ulnotriquetral, and scapholunate) and the TFCC when evaluating the diagnostic imaging parameters utilizing identical acquisition parameters [27].

\section{Magnetic resonance arthrography (direct and indirect)}

Direct MR arthrography is especially useful for evaluating TFCC as well as wrist ligaments (Fig. 4). Perforations of the TFCC contain high signal fluid on fat-suppressed T1weighted MR arthrographic images. With a traumatic TFCC tear, fluid or contrast material is usually present in the distal radioulnar joint. The presence of fluid alone in this location with no gadolinium should suggest synovitis or mechanical irritation of the distal radioulnar joint [28]. Limitations of MR arthrography, a fairly complicated and time-consuming technique compared with nonenhanced MR imaging, are its additional cost and invasiveness and the need to inject contrast medium into the joint [29]. 


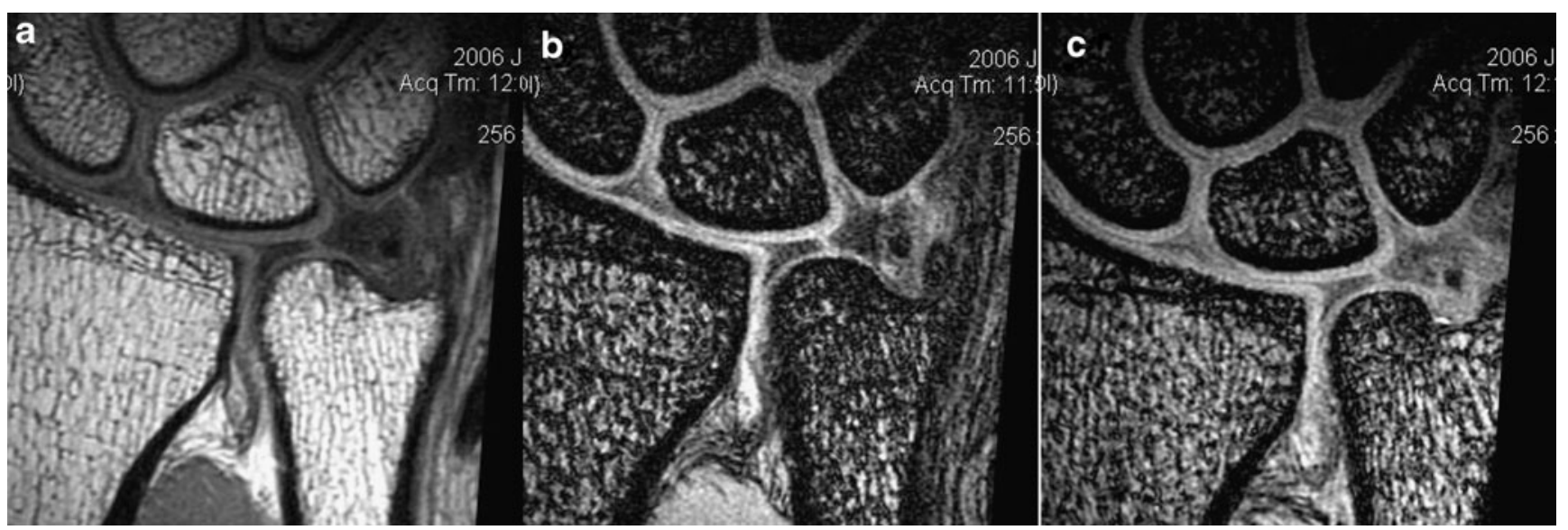

Fig. 3 High-resolution wrist MRI with a 2-inch coil at 3.0 T. a Twodimensional (2D) fast spin echo $(\mathrm{TR} / \mathrm{TE}=18,00 / 11.6$, field of view $6 \mathrm{~cm}$, matrix $192 \times 256$, slice thickness $1 \mathrm{~mm})$, b $2 \mathrm{D}$ gradient echo (GRE) $(\mathrm{TR} / \mathrm{TE} / \mathrm{FA}=500 / 15 / 40$, field of view $6 \mathrm{~cm}$, matrix $192 \times 256$,

Indirect wrist MR arthrography, based on the premise that intravenous (IV) contrast material administered will diffuse into the joint space over time, can also be performed. Since exercise not only increases vascular perfusion, but also increases vascular pressure, thereby improving diffusional flow into the joint, after the injection, the patient moves the wrist (can be passive or active) over a period of up to $20 \mathrm{~min}$ [30]. One preliminary study suggested that imaging accuracy in indirect wrist MR arthrography was excellent for the TFCC tears [31], whereas another study showed that indirect MR arthrography, when compared with non-enhanced MR imaging of the wrist, does not significantly improve the ability to evaluate the central disk of the TFCC [32]. Therefore, even though it has several advantages over direct MR arthrography, such as no fluoroscopic guidance, articular injection, and special MR scheduling, the usefulness of indirect wrist MR arthrography for TFCC is controversial. For example, a disadvantage of indirect MR arthrography is the direct vascular effect of intravenous contrast material that can become a clinical problem in the periphery of the TFCC slice thickness $1 \mathrm{~mm}$ ), and $\mathbf{c}$ 3D GRE TR/TE/flip angle $=31 / 9 / 10$, field of view $6 \mathrm{~cm}$, matrix $192 \times 256$, slice thickness $1 \mathrm{~mm}$ ) demonstrate a small central perforation of the triangular fibrocartilage complex (TFCC)

where contrast enhancement is seen and is not a sign of disease, but of normal vascularity.

\section{Differential diagnosis and clinical imaging}

\section{Bony injury}

Ulnar styloid fracture Ulnar styloid fractures occur as isolated injuries or in association with distal radius and other wrist fractures. Patients with these fractures present with a limited range of motion, grip weakness, and ulnarsided wrist pain that is exacerbated by ulnar deviation and twisting the wrist. A great number of ulnar styloid fractures $(65 \%)$ go on to nonunion, causing ulnar wrist problems [33]. Depending on the location and stability of the distal radioulnar joint (DRUJ), such nonunion of fractures has been classified into two types. Type 1 nonunions are located at the tip of the styloid; the TFCC remains intact and the DRUJ is stable. In type 2 nonunions, the fracture occurs at the base of the styloid and the attachment to the TFCC is disrupted, resulting in an unstable DRUJ [34]. MR

Fig. 4 a Coronal fat-suppressed T1-weighted MR arthrographic image $(\mathrm{TR} / \mathrm{TE}=650 / 15)$, b sagittal proton density-weighted image $(\mathrm{TR} / \mathrm{TE}=2,000 / 32)$ show an articular disc tear of the TFCC (arrow) with contrast material within the distal radioulnar joint (arrowhead). Images are suggestive of a peripheral TFCC tear with mild extravasation of the contrast agent (curved arrow)
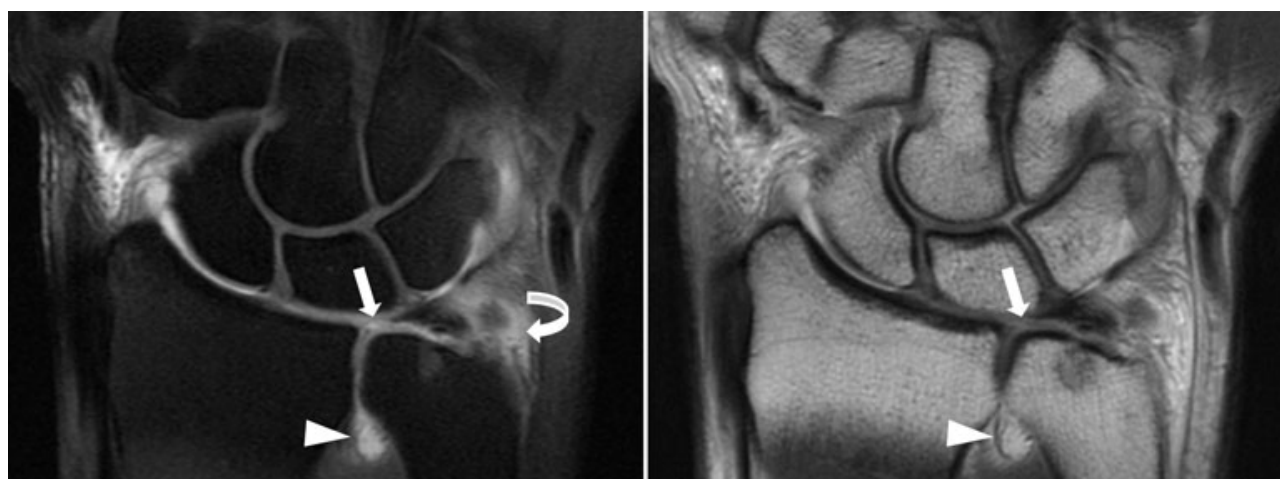
can be used to access the fracture and the TFCC. MR arthrography, in particular, is useful for evaluating the peripheral TFCC injury.

Hamate fracture Even though a high index of suspicion is required to identify them, hamate fractures account for $1.7 \%$ of all carpal fractures [13] and are usually nondisplaced. More common fractures of the hamate are fractures of the hamate hook that typically result from direct compression of the handle of the racket against the protruding hook and often occur in athletes participating in racket sports. [35]. Much more uncommon than fractures of the hamate hook are fractures of the body of the hamate that may occur as a result of an axial force that is transmitted through the metacarpals or a direct blow to the ulnar aspect of the wrist and are commonly associated with dislocations of the fourth and fifth carpometacarpal joints, particularly the coronally oriented fractures [35]. Occasionally, hamate body fractures are associated with perilunate dislocations.

The radiographic assessment of the hamate is a clinical challenge, especially the hook, given that routine PA and lateral views of the wrist are rarely useful in demonstrating the fracture. A number of techniques have been described that may show the fracture: semi-supine, oblique lateral view, and carpal-tunnel radiography [36]. Radiographic signs of hamate hook fracture include absence of the hook in an acute displaced fracture or sclerosis in the area of a healing hook fracture [13]. An accessory ossicle can mimic a hook fracture. In cases of clinical findings suggesting a fracture without apparent radiographic evidence, a CT should be ordered [37]. CT is considered the examination of choice, with sensitivity and specificity approaching $100 \%$ (Fig. 5). CT can help to determine the degree of fracture displacement, a critical point that aids therapeutic decision making.
Fifth metacarpal base fracture Another cause of ulnarsided wrist pain can be a fracture of the base of fifth metacarpal. As in other metacarpal bones, the fracture can be oblique, horizontal, or vertical and, since it is prone to dislocation, radiologists should report any possible intraarticular component of the fracture. The fifth carpometacarpal joint consists of the concave facet of the hamate and the corresponding convex proximal articular surface of the fifth metacarpal. The radial aspect of the base of the fifth metacarpal articulates with the fourth metacarpal. The extensor carpi ulnaris tendon inserts at the dorsoulnar aspect of the base of the fifth metacarpal. Providing additional reinforcement is the pisometacarpal ligament, a distal extension of the flexor carpi ulnaris [38]. In the case of intra-articular fracture with dislocation, the ulnar fragment will be displaced ulnarly and proximally due to muscle traction (extensor carpi ulnaris); such findings are important for treatment planning and surgery, if necessary. Routine PA and lateral radiographs constitute the initial diagnostic imaging approach and are usually sufficient for the diagnosis. Oblique views and radiographs with stress (valgus and varus) can also be performed. For more detailed anatomical information, CT can be used and, in some cases, MR is helpful in evaluating ligaments, tendons, and nondisplaced fractures.

Pisiform fracture Fracture of the pisiform, a sesamoid bone enclosed within the flexor carpi ulnaris tendon, articulating with the triquetrum dorsally, is uncommon (1$2 \%$ of all carpal fractures), but when it does occur, it is frequently associated with other injuries to the carpus or distal radius [13]. Although the exact mechanism is often difficult to determine, the pisiform fracture may result from either direct trauma or muscular avulsion. In fact, the superficial location of the pisiform makes it particularly vulnerable to direct trauma. Avulsion fracture results when
Fig. 5 a Axial and b reformatted sagittal CT of the wrist in a patient with hamate fracture (arrows)
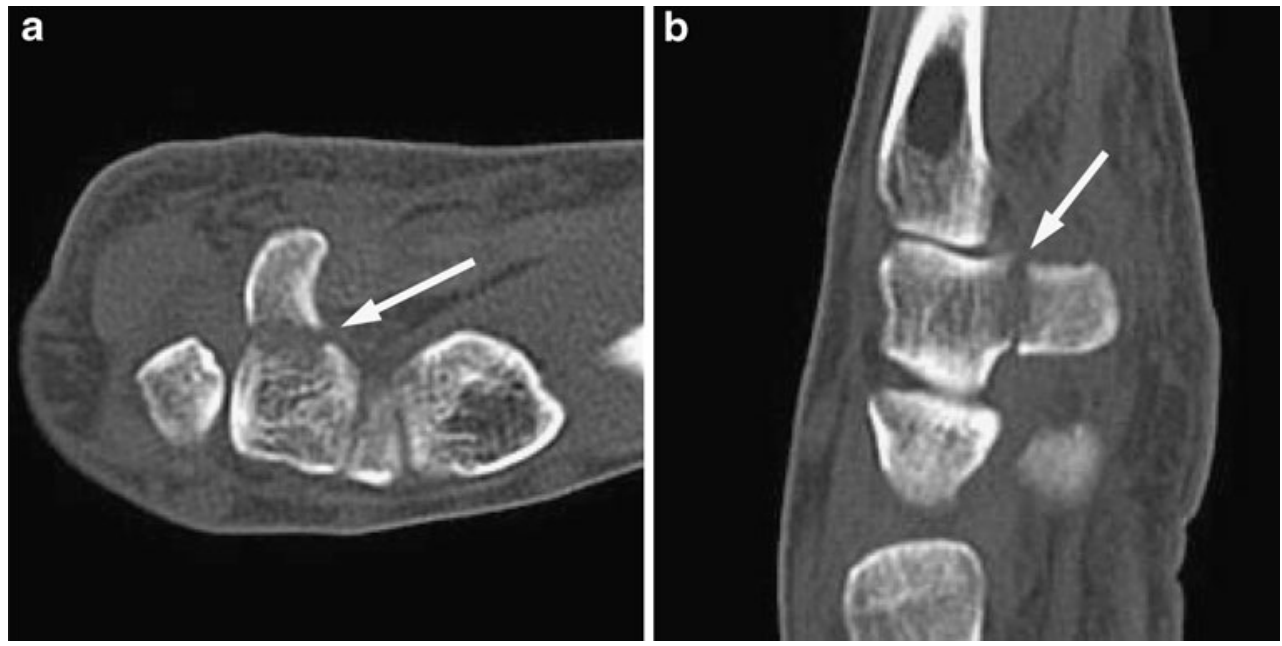
the flexor carpi ulnaris resists forcible hyperextension of the wrist. Typically, this mechanism produces either an osteochondral fracture or avulsion of the distal portion of the pisiform [39].

Pisiform fractures may be linear, comminuted, or chip type with or without associated pisiform dislocation [13]. Since radiographs are readily available and inexpensive, it is advisable to use them as the first step in evaluating possible pisiform fracture. Most fractures of the pisiform will be detected on routine views. If routine radiographs of the wrist fail to demonstrate the fracture, a supinated oblique view or carpal tunnel view is indicated. CT and MR imaging examination may follow if suspicion of fracture is high, other examinations are negative, and the patient remains symptomatic. A pitfall in interpretation is the presence of multiple ossification centers of the pisiform, a normal variant [39].

It is important not to miss a fractured pisiform because delayed diagnosis may lead to long-term disability. Complications may include pisotriquetral chondromalacia or subluxation and the presence of loose fragments of bone or cartilage in the joint space [40] as well as ulnar nerve injury because of close proximity to the ulnar nerve [35].

Kienböck's disease With an unknown cause, an uncertain natural history, and occurring twice as frequently in men as in women, Kienböck's disease is a form of osteonecrosis affecting the lunate. It most often occurs in the dominant hand as the patient is between the ages of 20 and 40 years. Clinical features are dorsal wrist pain, but it can also manifest as ulnar-sided wrist pain, usually associated with synovitis, limitation of movement, and decrease in grip strength. In advanced disease the symptoms are related to osteoarthritis of the wrist [41]. Some hypotheses to explain the changes in the lunate include [42]:

1. Interruption of the blood supply leading to secondary osteonecrosis and fracture

2. Damage to the blood supply by a primary lunate fracture

3. Repetitive stressing of the lunate at the point where the relatively compliant triangular fibrocartilage is attached to the radius, leading to subcortical microfractures

Several studies have been published on the risk factors for Kienböck's disease, including one that confirmed Hulten's observation that the ulna was relatively shorter than the radius in $78 \%$ of patients with Kienböck's disease compared with $23 \%$ of the normal population [43]. Theoretically, the short ulna increases the shearing forces and stress on the lunate bone, which may be a contributing factor in the development of aseptic necrosis. However, Kienböck's disease does not inevitably occur when a gross discrepancy exists between the lengths of the radius and ulna [44].
In a scenario of wrist pain (dorsal and ulnar) and reduced range of motion with or without a history of trauma, diagnosis is made using radiographs; however, MR imaging can be helpful in the early detection of the disease (Fig. 6) [45]. A CT is also useful to demonstrate fracture or fragmentation of the lunate. Delays in diagnosis are common with this condition; the average duration of symptoms before diagnosis is $1-2$ years [46].

Kienböck's disease can be classified into four stages [47-49].

Stage I. At stage I, radiographs are both sensitive and nonspecific for the diagnosis. Bone scintigraphy may be helpful but is poor in differentiating fractures, osteochondral lesions, erosions, and the spectrum of degenerative changes that present as subchondral sclerosis. MR imaging offers comparable or greater sensitivity and improved specificity compared with that available from radiographs. Focal or diffuse low signal intensity is seen on T1-weighted images in affected areas of marrow involvement.

Stage II. The lunate exhibits increased density, but its size and shape are unchanged, appearing as low signal intensity on T1-weighted images. Short tau inversion recovery images (STIR) or fatsuppressed $\mathrm{T} 2$-weighted images demonstrate areas of increased signal intensity in patients who show sclerosis on corresponding radiographs. Decreased height of the radial aspect of the lunate may be seen in late stage II disease.

Stage III. The lunate has collapsed, allowing the capitate to migrate proximally. In stage IIIA, the scaphoid maintains a normal position relative to the rest of the carpus, but in stage IIIB, it has moved into a position of fixed rotation, as shown by the scaphoid "ring" sign.

Stage IV. Stage IV is characterized by degenerative arthrosis of the lunate (collapsed) and carpus. No regions of increased signal intensity appear on T2-weighted or STIR images at this advanced stage of disease. Fragmented portions of the lunate are usually identified with low signal intensity on T1- and T2-weighted images.

\section{Ligamentous and tendinous disorders}

Triangular fibrocartilage complex injury The imaging evaluation of the TFCC is still a challenge. Traditional imaging tools for investigation of wrist pain include radiographs, wrist arthrography, CT, and MR imaging. Plain radiography is not useful in characterizing TFCC abnormalities. However, radiographic findings associated 
Fig. 6 Kienböck's disease Radiographs of a the affected side (arrow) and b the nonaffected side. c Coronal proton-density-weighted $(\mathrm{TR} / \mathrm{TE}=1,582 / 15)$ and $\mathbf{d}$ coronal GRE (TR/TE/flip angle $=379 / 12 / 40$ ) $\mathrm{MR}$ imaging of the wrist in the same patient with Kienböck's disease demonstrate mixed bone marrow edema and sclerosis with slightly collapsed lunate (arrows)
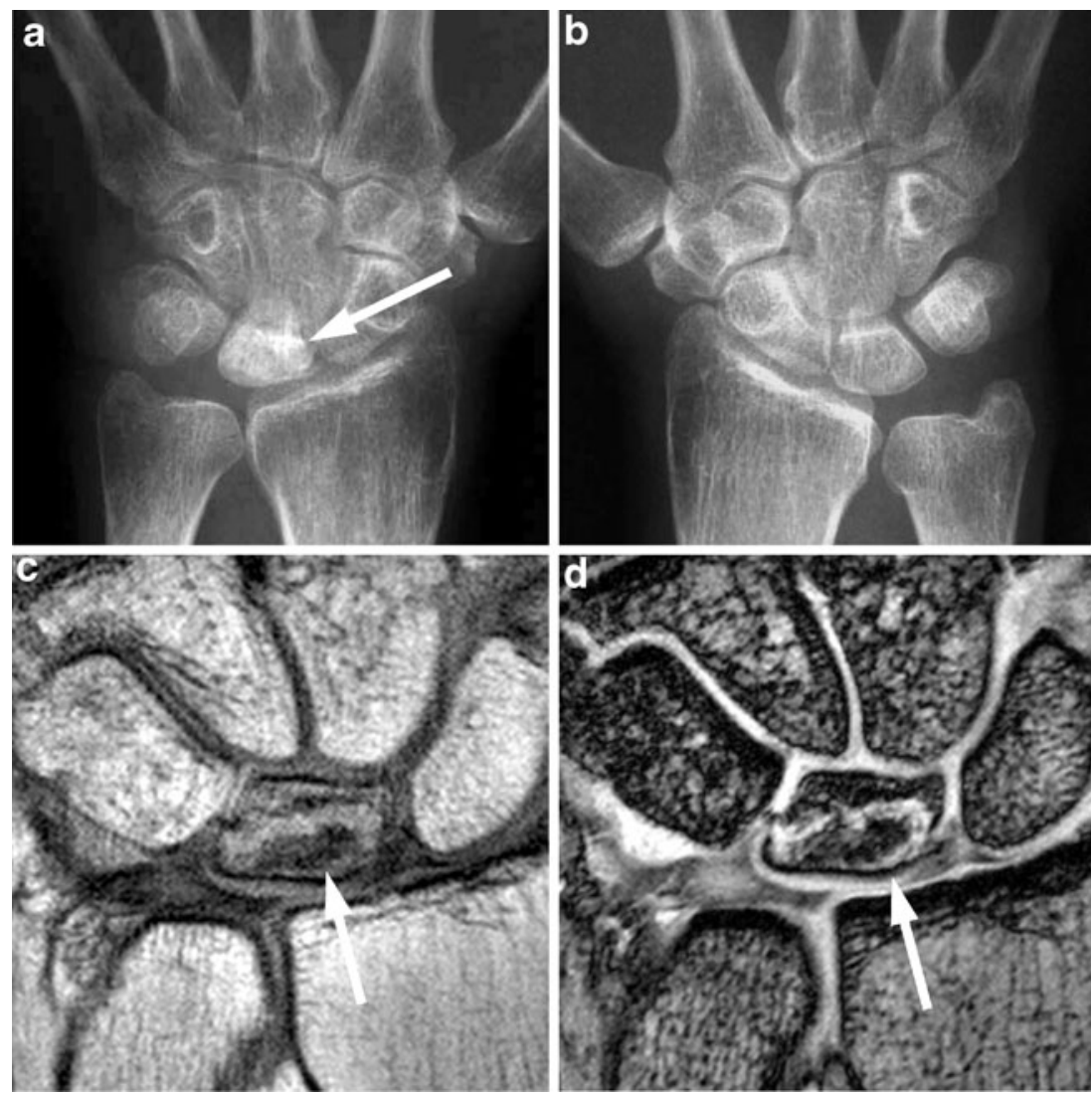

with abnormalities of the complex, such as positive ulnar variance, the presence of an ulnar styloid fracture associated with peripheral avulsion of the TFCC, and avulsion fracture of the fovea of the ulna, that indicate injury at the site of attachment of the proximal lamina of the TFCC, may be encountered [3]. The neutral PA is the best view to measure ulnar variance. In addition, radiographs enable us to assess chondromalacia of the lunate or ulnar head, degenerative joint disease of the DRUJ, lunotriquetral or scapholunate instability, dorsiflexed intercalated segment instability (DISI), or volar flexed intercalated segment instability (VISI).

Although there is some disagreement regarding the optimal technique for compartmental injection (single injection, triple injection), the role of arthrography in the diagnosis of TFCC defects is well established. Its challenge is its lack of specificity with a high incidence of findings on the contralateral asymptomatic side [50]. MR imaging is, however, a useful imaging tool for diagnosing TFCC injuries [21, 51-55] with Potter et al. reporting sensitivity for high-resolution MR imaging of $100 \%$, specificity of $90 \%$, and accuracy of $97 \%$ with the use of arthroscopy as standard treatment [54]. Also, in a recent report [56], highresolution MR images obtained using a microscopy surface coil allowed assessment of each TFCC component and showed high accuracy for diagnosing radial attachment injury, disc injury, and triangular ligament injury of the TFCC (100\% sensitivity; 100\% specificity) (Fig. 7). This coil is not widely available and currently restricted to a single vendor. Given MR's strengths, MR arthrography is probably the most accurate test for TFCC lesions and is useful for evaluating TFCC as well as other intrinsic wrist ligaments. To conduct this evaluation, clinicians see the high signal fluid contained by perforations of the TFCC on fat-suppressed T1-weighted MR arthrographic images. With a traumatic TFCC tear, fluid or contrast material is usually present in the DRUJ. Conventional MR imaging sometimes does not adequately reveal the peripheral attachment of the TFCC because the ulnar attachment is often obscured by an intermediate signal surrounding loose vascular connective tissue on proton density-weighted images and $\mathrm{T} 2 *$-weighted images. MR arthrography with fat-suppressed $\mathrm{T} 1$-weighted images may provide better detection of ulnar-sided peripheral TFCC tears than conventional MR imaging. The terms communicating (full-thickness) and noncommunicating (partial thickness) defects are used in the discussion of TFCC abnormalities. The presence of contrast material in the DRUJ after radiocarpal opacification or in the radiocarpal compartment after DRUJ injection indicates a communicating defect in the TFCC (articular disc). Noncommunicating tears involving the proximal and distal aspects of the 

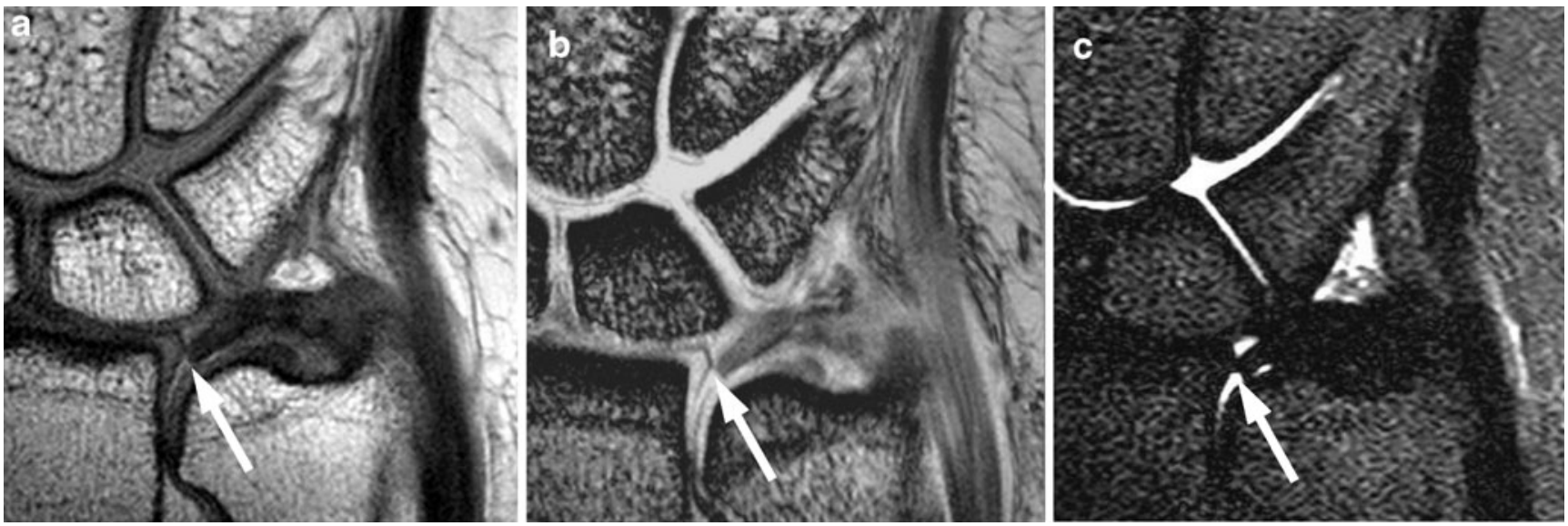

Fig. 7 High-resolution MR images of TFCC tear obtained using a microscopy surface coil (arrows). a Coronal proton-density-weighted image (TR/ $\mathrm{TE}=1,992 / 15)$, $\mathbf{b}$ GRE image (TR/TE/flip angle=518/16/40), and $\mathbf{c}$ coronal STIR image (TR/TE/TI=2,206/90/150) demonstrate a type ID FCC tear

TFCC can be demonstrated following injection of the DRUJ and radiocarpal joint respectively [3]. Noncommunicating TFCC defects, which typically are located on the proximal side of the TFC near its ulnar attachment, have a more reliable association with symptomatic wrists than do communicating defects [57]. Radial-sided communicating defects described in the literature as post-traumatic commonly are seen bilaterally and in asymptomatic wrists [57]. The TFCC with associated bony fracture is adequately analyzed using multidetector CT arthrography. The disk proper is clearly seen on a coronal image from its cartilaginous insertion on the radial sigmoid notch to its ulnar attachment [16].

Ultrasound continues to develop as a viable imaging tool in the assessment of musculoskeletal disorders. The advent of high-resolution probe technology with transducer frequencies (above $12 \mathrm{MHz}$ ) has expanded the variety of superficial anatomical structures amenable to US evaluation [58]. Chiou et al. compared high-resolution ultrasound findings of the triangular fibrocartilage with arthrography [59]. Besides that study and despite improvements in technology [60], little attention has been paid to US of the TFCC.

Extensor carpi ulnaris disorder Disorders of the extensor carpi ulnaris (ECU) tendon include subluxation, dislocation, tendinopathy, tenosynovitis, and rupture. This tendon passes through the sixth extensor compartment, which is a fibro-osseus tunnel over the distal $1.5-2.0 \mathrm{~cm}$ of the ulna [61]. The extensor retinaculum covers but does not adhere to the tunnel [62]. Because of the large forces applied at the ECU subsheath, especially during supination, palmar flexion and ulnar deviation of the hand, the tendon can sublux and dislocate [61, 62]. Historically, this condition has been diagnosed clinically by palpation of the subluxating ECU tendon over the dorsoulnar aspect of the wrist.
With conventional radiography, arthrography, and CT often appearing normal, confirmation of the diagnosis can be challenging $[63,64]$. US can be very useful in some cases that show, during dynamic maneuvers, the excursion and subluxation of the tendon, and dynamic ultrasound is an effective and noninvasive method of diagnosing ECU tendon subluxation [64]. MR imaging may suggest nonspecific synovitis of the ECU sheath, but without revealing dynamic instability [65]. However, tendinopathy, tenosynovitis, and tendon rupture are well evaluated by MR imaging. In tendinopathy, the tendon is thickened, and the signal is increased in both T1- and T2-weighted images. Fluid around the tendon within the tendon sheath is suggestive of tenosynovitis. However, since the sixth compartment is the second most common location for it in the upper extremity, a diagnosis of stenosing tenosynovitis is a possibility [66]. More common in athletes than in non-athletes, tendon rupture can be seen on both MR imaging and US as a complete discontinuity of tendon fibers (Fig. 8).

Flexor carpi ulnaris tendinitis As mentioned, pain around the tendons of the wrist can be caused by tendinitis, tenosynovitis (also stenosing tenosynovitis), or rupture. An important aspect of the FCU is its lack of a sheath [67]. Therefore, pain and palpable tenderness along the course of the FCU indicate FCU tendinitis that may be associated with repetitive forceful ulnar deviation that often appears without an obvious event [61]. The most common presentation is the calcified tendinitis of the FCU. Usually, tangential radiographs of the volar and ulnar aspects of the wrist reveal calcium distal to the ulna. MR imaging reveals the signs of tendinitis with increased signal on T1- and T2weighted images and can also demonstrate the calcification deposition of calcified tendinitis, especially with gradientecho sequences. 
Fig. 8 a Coronal (TR/TE/flip angle $=533 / 16 / 40$ ) and $\mathbf{b}$ axial $(\mathrm{TR} / \mathrm{TE} / \mathrm{flip}$ angle $=481 / 15 / 40)$ GRE MR imaging of the wrist in a patient with partial extensor carpi ulnaris tendon tear (arrows)
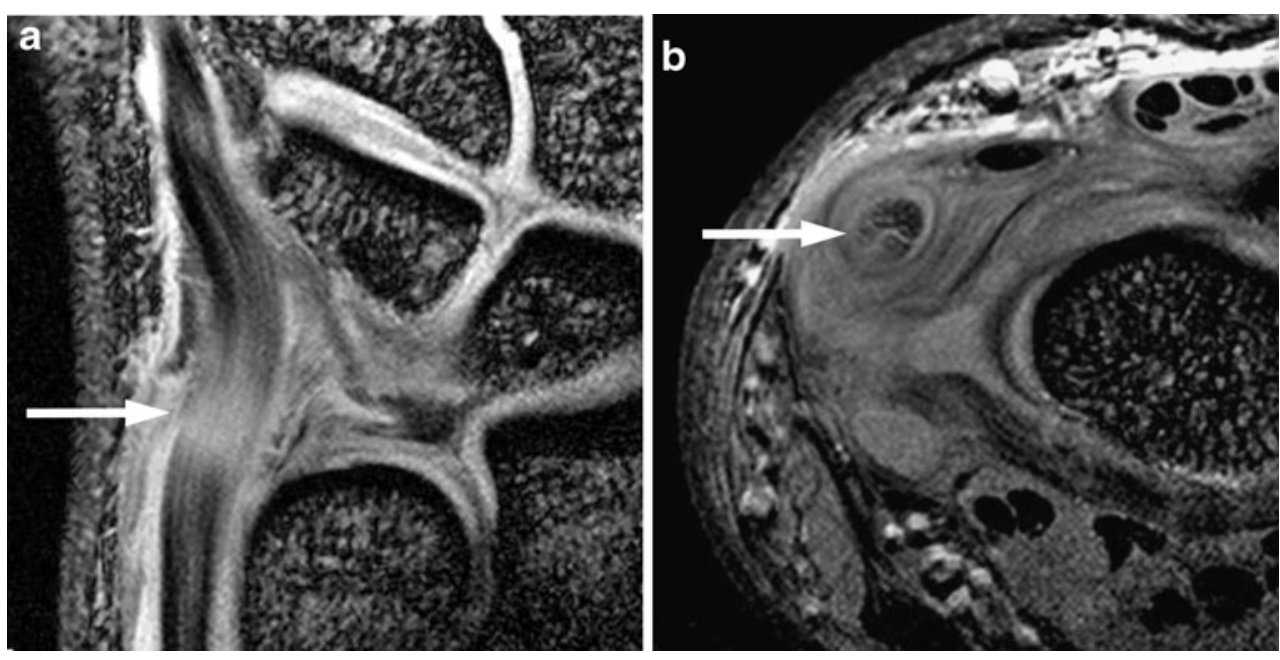

\section{Neurological pain-Guyon's canal syndrome}

Entrapment of the ulnar nerve in Guyon's canal (Guyon's canal syndrome) can be a cause of ulnar-sided wrist pain with the common causes of ulnar nerve compression including carpal bone fractures, deformity of the carpal bone following osteoarthritis, ganglions, anomalous muscles, and ulnar artery aneurysms $[68,69]$.

With a limited ability in diagnosing Guyon's canal syndrome, radiography is useful for evaluating the abnormality of bones such as carpal bone fractures (especially the hook of the hamate) and the deformity of carpal bone following osteoarthritis.

The advantages of US over MR imaging may include the detection of anomalous muscles that compress the ulnar nerve. Also, since they are indistinguishable from normal muscle, anomalous muscles may not be recognized as abnormalities on MR imaging [70]. US has the benefit of allowing dynamic imaging of muscle contraction with movement that may present as a mass causing neural compression [71]. Comparative imaging of the contralateral side is helpful for the detection of anomalous muscles.

As CT depicts much more bony detail than radiography, it is useful to detect fractures, particularly fractures of the hook of the hamate that are not evident on radiographs [15, 72]. However, CT has a limited ability in visualizing soft tissue structures in Guyon's canal [73]. Therefore, other imaging modalities for visualizing the soft tissues are preferable.

Magnetic resonance imaging is useful for detecting abnormalities of the ulnar nerve, including swelling of the nerve proximal to Guyon's canal, flattening of the nerve within Guyon's canal, and increased signal intensity on T2weighted images [70]. MR imaging is also useful in detecting lesions within or adjacent to Guyon's canal, such as ganglion, lipomas, anomalous muscles, ulnar artery false aneurysm, hypertrophy of the flexor carpi ulnaris tendon, hypertrophy of the palmar carpal ligament, osteoarthritis of the pisiform-triquetral joint, and fractures [74].

\section{Carpal instability}

Lunotriquetral dissociation Lunotriquetral dissociation is the second most common ligamentous cause of carpal instability [75]. Disruption of the lunotriquetral ligament (LTL) causes a dynamic or static instability of the lunotriquetral joints. An increased frequency of LTL tears in association with degenerative tears of the triangular fibrocartilage has been reported [76]. Typical imaging findings of lunotriquetral dissociation are described next.

Posteroanterior radiography may reveal the increase in the lunotriquetral joint space width when complete dissociation develops [77]. However, radiographic examinations often show no abnormalities. Lateral views may show static palmar flexion of the lunate; it occurs in only a minority of cases as it requires the presence of a tear of the dorsal radiocarpal ligament [78].

Arthrography can demonstrate leakage or pooling of the contrast medium at the lunotriquetral interspace [79]. However, age-related perforations of the LTL proximal zone, other communications between the radiocarpal and midcarpal joints, and asymptomatic LTL tears on arthrography of the normal wrist have been reported [79]. Therefore, the results of arthrography must be correlated with clinical examination findings.

Computed tomographic arthrography can combine the detailed CT view of bony anatomy with a clear image of the ligamentous structures of the wrist to allow a precise assessment of interosseous ligament injuries [15]. Schmid et al. reported using cadaver wrists in which palmar and central segment tears of the LTL are almost equal for multi-detector row CT arthrography and MR imaging, with a much higher inter-observer reliability for CT arthrography. CT arthrography is significantly superior to 
MR imaging in the detection of dorsal segment tears of the LTL [80].

Although many previous MR studies have discussed LTL injuries in the coronal plane, the axial view may be better for assessing LTL injuries as the dorsal and volar portions of the LTL are biomechanically more important than the proximal portion [81]. Complete tears of the LTL on MR imaging have been classified by either abnormal ligament morphology to the point of absence of the entire ligament or by the presence of fluid through the entire ligament on T2-weighted images [51]. Partial tears of the LTL have been diagnosed by two criteria: the presence of fluid through a portion of the ligament and partially altered ligament morphology visualized in any sequence [82]. Direct MR arthrography has several advantages over nonenhanced MR imaging of the wrist in diagnosing LTL injuries. First, the joint cavities of the wrist can be fully expanded so that most of the ligamentous and capsular structures are stretched and can be directly visualized and evaluated [29]. Second, the high signal of the contrast agent leads to excellent delineation of all parts of ligaments that show low signal intensity. Third, MR arthrography can precisely localize and quantify LTL leakages to have a significant impact on diagnosis and treatment methods [32]. On the other hand, indirect MR arthrography does not significantly improve the ability to evaluate the LTL [32].

Midcarpal instability Midcarpal instability is a dynamic disorder, one that is associated with the tear or an insufficiency of the scaphocapitate ligament and triquetrohamocapitate ligament [83, 84]. Patients with midcarpal instability may have a wrist clunk when moving from radial to ulnar deviation as a result of the proximal carpal row snapping suddenly from a palmar flexed position to a dorsal flexed position instead of making a smooth synchronous transition [83-85].

As static radiography is often normal, dynamic radiography with the use of videofluoroscopy is the imaging study of choice. Careful scrutiny of the videos indicated that the proximal carpal row was not rotating smoothly from flexion to extension as the wrist moved from radial to ulnar deviation [86]. Using a manually stressed lateral view in an attempt to reproduce the clunk, fluoroscopy can depict the shift of the proximal carpal row from a palmar flexed position to a dorsal flexed position $[83,86]$.

Magnetic resonance imaging demonstrates the scaphocapitate ligament and triquetrohamocapitate ligament as structures of low signal intensity that form an inverted "V" joining the proximal and distal carpal rows [87, 88]. However, the accuracy of MR imaging in depicting disruption of these ligaments in patients with clinically evident midcarpal instability has not yet been defined [83]. MR imaging can also reveal degenerative changes in the proximal pole of the capitates, such as marrow edema, subchondral cysts, and sclerotic changes [89].

\section{Radioulnar joint disorder}

Distal radioulnar joint instability Acute or chronic DRUJ instability can be a cause of ulnar-sided wrist pain. Fractures of the distal radius or ulna that alter the biomechanics of the DRUJ, are capable of producing radioulnar joint instability $[90,91]$. In addition, soft tissue injury including the TFCC, dorsal and palmar radioulnar ligaments, interosseous membrane, and joint capsule can produce instability of the DRUJ [90].

Posteroanterior radiography may demonstrate a fleck fracture with an avulsion of the TFCC, an ulnar styloid fracture or nonunion, shortening of the radius, and joint widening between the radius and ulna [90]. Ulnar variance should be measured on the PA radiograph made with the forearm in neutral rotation and the shoulder and elbow in $90^{\circ}$ of flexion [92]. On the lateral radiography, dislocation of the radioulnar joint can be diagnosed with comparison to that on the unaffected side. Arthrography is also useful for identifying tears of the TFCC that are often associated with radioulnar joint instability.

The best study with which to visualize a subluxation or dislocation is a CT examination of both wrists performed in both pronation and supination [90]. Several CT methods have been proposed for diagnosing radioulnar joint subluxation, and have been proved to be useful for evaluating patients suspected of having radioulnar joint instability [93-95]. CT is also useful for revealing radioulnar joint incongruity.

Magnetic resonance imaging or MR arthrography is useful for identifying tears of the TFCC that are often
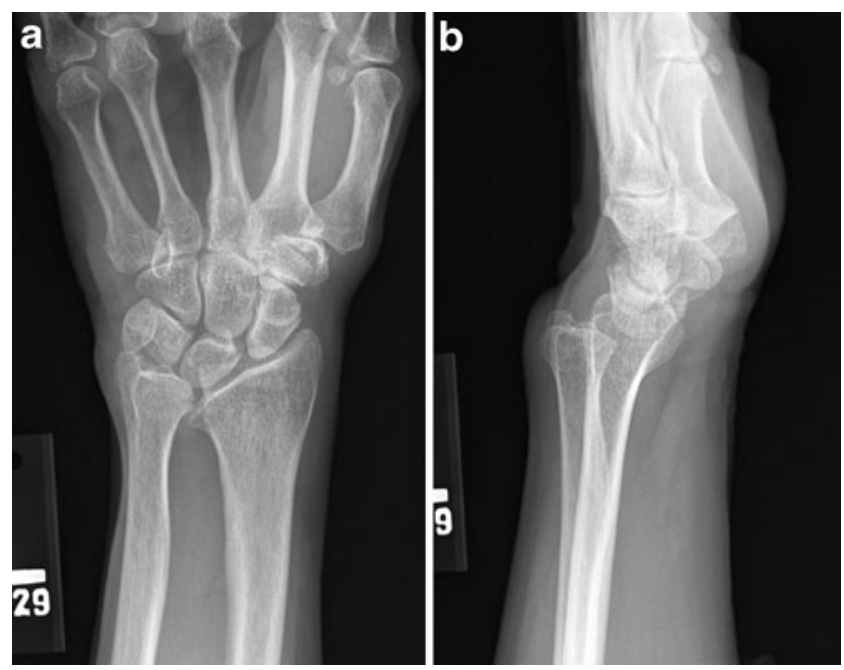

Fig. 9 Radiograph of Madelung's deformity. a posteroanterior view and $\mathbf{b}$ lateral view 


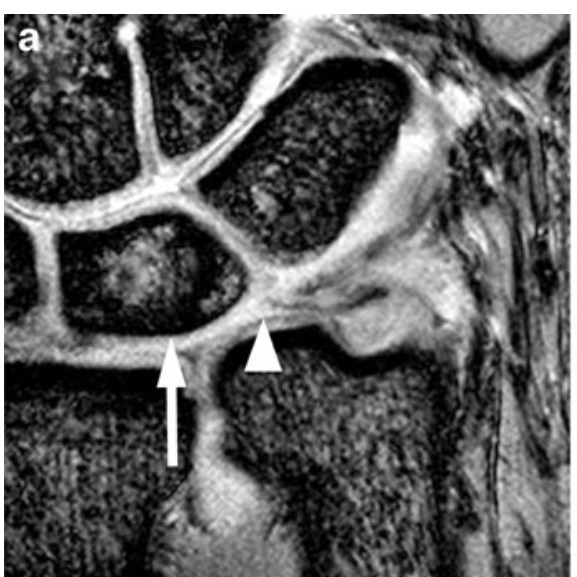

Fig. 10 Magnetic resonance images of the ulnar impaction syndrome. a Coronal 2D GRE $(\mathrm{TR} / \mathrm{TE} /$ flip angle $=533 / 16 / 40)$, b proton-densityweighted $(\mathrm{TR} / \mathrm{TE}=1531 / 15)$, and $\mathbf{c} \mathrm{STIR}(\mathrm{TR} / \mathrm{TE} / \mathrm{TI}=4389 / 90 / 150)$

associated with DRUJ instability. Detailed MR findings are discussed in the TFCC section under Ligamentous and tendinous disorders above.

Madelung's deformity Plain radiography is commonly used for the assessment of Madelung's deformity, which is characterized by a shortened radius that curves ulnarly and volarly, a prominent ulna head that projects dorsally from the wrist, and a triangular arrangement of the carpal bones [96]. Madelung's deformity may affect not only the distal radius, but also the entire radius [97]; thus, the radiographic examination should include the forearm as well as the wrist. McCarroll et al. reported that ulnar tilt, lunate subsidence, and palmar carpal displacement were reliable and reproducible radiographic measurements for quantifying the severity of Madelung's deformity [98]. Radiographs of the forearm might show a shorter radius images show a bone marrow edema and sclerosis in the lunate (arrows). Diffuse degenerative TFCC tear is noted (arrowhead)

and ulna and an extensive deformity of the forearm (Fig. 9) [97].

\section{Impaction syndromes}

Ulnar impingement syndrome Ulnar-sided wrist pain can also result from ulnar impingement syndrome, a condition in which the shortened ulna impinges on the distal radius [99]. The clinical manifestation of ulnar impingement syndrome can be similar to that of ulnar impaction syndrome; however, patients with ulnar impingement syndrome will generally experience a great deal of discomfort on pronation and supination of the forearm [100].

Posteroanterior radiography of ulnar impingement syndrome demonstrates a shortened ulna proximal to the level of the sigmoid notch of the radius and the radioulnar convergence [99]. The stress-loaded radiological view described by

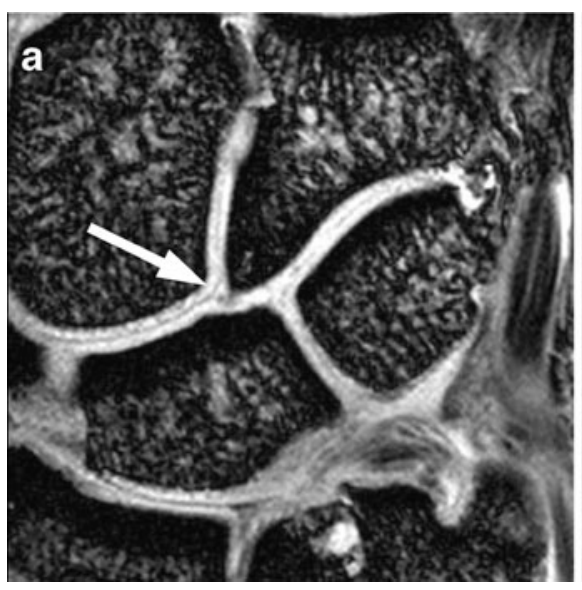

Fig. 11 Magnetic resonance images of the hamatolunate impingement syndrome. a Coronal 2D GRE image (TR/TE/flip angle $=531 / 16 / 40)$, b proton-density-weighted image $(\mathrm{TR} / \mathrm{TE}=1,531 / 15)$, and c STIR
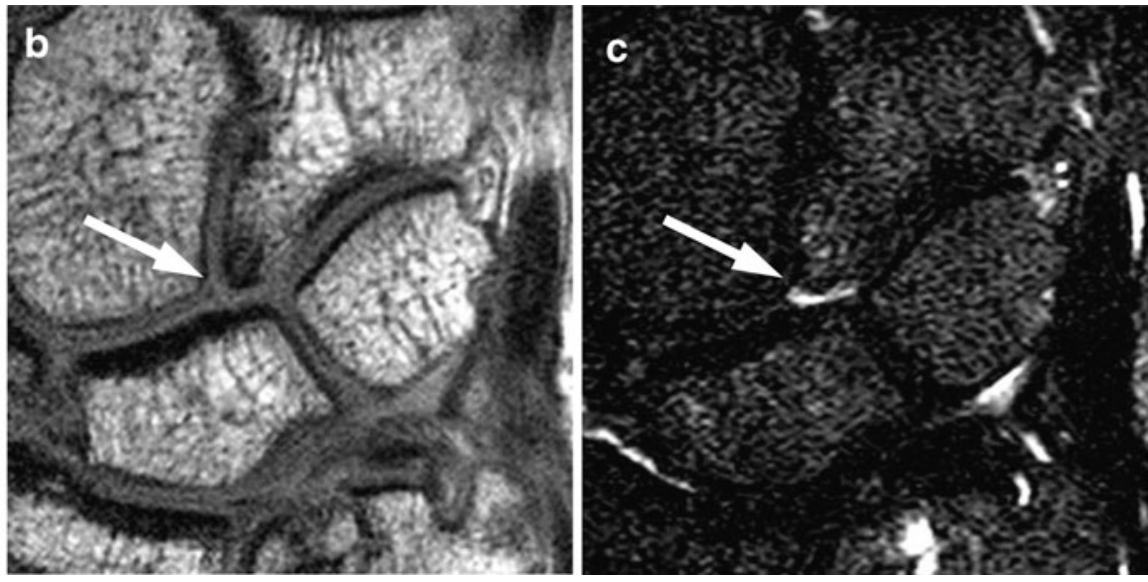

$(\mathrm{TR} / \mathrm{TE} / \mathrm{TI}=4,389 / 90 / 150)$ images show articulation between the hamate and lunate, bone marrow edema, and chondromalacia of these bones (arrows) 
Lees et al. is useful to confirm the presence of the radioulnar convergence [101]. Radiography may also show scalloping, sclerosis, and bone hypertrophy corresponding to the site of impingement [99].

Magnetic resonance imaging is useful for earlier diagnosis, showing subtle sclerosis and bone edema at the corresponding level of the radius and the ulna $[100,102]$. In advanced stages, scalloping and sclerosis along the ulnar margin of the distal radius cephalad to the sigmoid notch, sclerosis in the ulnar seat, and bony spurs or osteophytes in both margins are clearly visualized on MR images [102].

Ulnar impaction syndrome Ulnar impaction syndrome is caused by the impaction between the ulnar carpal bone and the ulnar head, a phenomenon that can also lead to ulnarsided wrist pain and that tends to occur when there is positive ulnar variance and a degenerative/osteoarthritic condition of the ulnar side of the wrist related to excessive load-bearing across the ulnar carpus, TFCC, and ulnar head [100].

A radiograph of ulnar impaction syndrome most commonly shows positive ulnar variance [103]; however, it may also show neutral or negative ulnar variance. Tomaino reported that pronated grip radiography is useful in determining the increase in ulnar variance and the impaction between the ulnar carpus and the dome of the ulnar

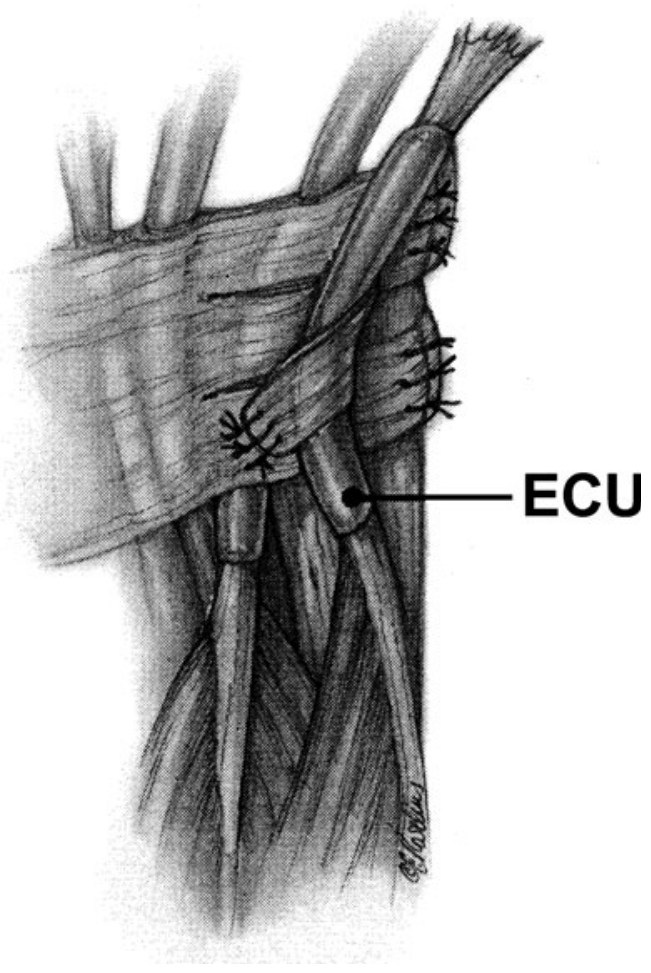

Fig. 12 Reconstruction of the extensor carpi ulnaris (ECU) subsheath using adjacent extensor retinaculum. (Reprinted with permission from [152])

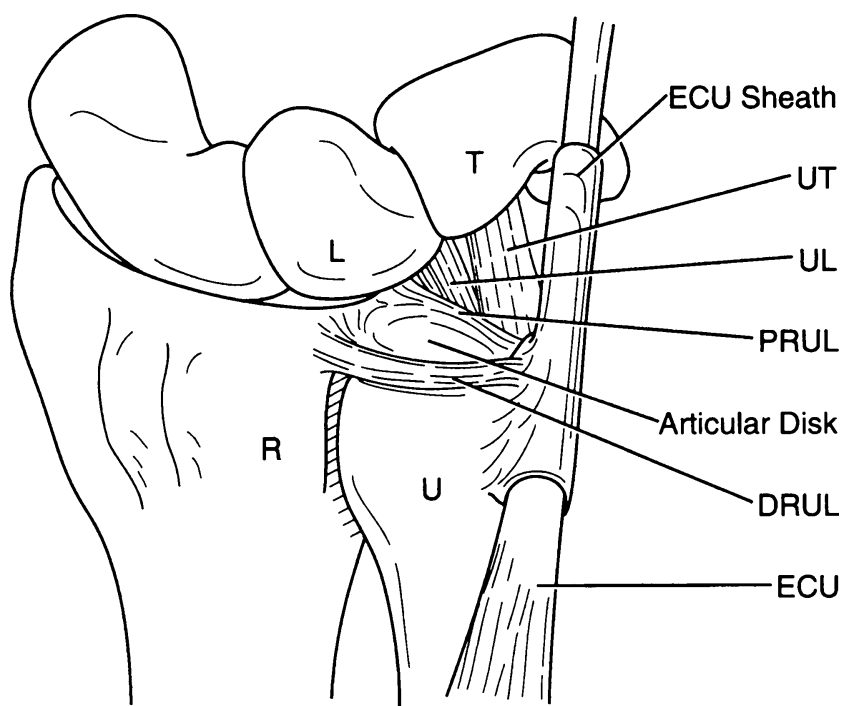

Fig. 13 Illustration of the wrist with the TFCC. $R$ radius, $U$ ulna, $E C U$ extensor carpi ulnaris, DRUL dorsal radioulnar ligament, $P R U L$ palmar radioulnar ligament, $L$ lunate, $T$ triquetrum, $U L$ ulnolunate ligament, UT ulnotriquetral ligament. (Reprinted with permission from [153])

head [104]. Radiography may show shortening of the radius following a distal radius fracture, a previous surgical procedure, or premature physeal arrest of the distal radius [103]. It may also show subchondral changes that may include sclerosis or cystic change at the ulnar aspect of the proximal lunate, triquetrum, and ulnar head [20].

Magnetic resonance imaging is useful to detect not only the anatomical abnormality of the bone, but also secondary changes in the ulnar impaction syndrome such as degeneration or defect of cartilage, marrow edema, subchondral cysts, and sclerotic changes at the affected site (Fig. 10) $[20,102,105]$. These changes are usually observed much earlier in MR imaging than in radiography.

Hamatolunate impingement syndrome Another cause of ulnar-sided wrist pain, though uncommon, is hamatolunate

Table 1 Palmer classification for triangular fibrocartilage complex (TFCC) injury. LTL lunotriquetral ligament
Class I (Traumatic)
A Central perforation
B Ulnar avulsion
C Distal avulsion
D Radial avulsion
Class II (Degenerative)
A TFCC wear
B TFCC wear with lunate and/or ulnar chondromalacia
C TFCC perforation with lunate and/or ulnar chondromalacia
$\mathrm{D} C$ and LTL perforation
E D and ulnocarpal arthritis 
Fig. 14 Triangular fibrocartilage complex (TFCC) lesions as described by Palmer. Type I lesions are traumatic in etiology and are subdivided into types IA through ID. a Type IA, central traumatic tear typically located within the sagittal plane within $2 \mathrm{~mm}$ from the radial articular surface. b Type IB, medial avulsion lesion that is sometimes associated with an ulnar styloid fracture. $\mathbf{c}$ Type IC, distal avulsion lesion with associated ulnocarpal ligament tears. d Type ID, lateral avulsion lesion with tears of the radioulnar ligament and articular disk attachments to the radius. Type ID lesions may have an associated sigmoid notch fracture. e Type II lesion, degenerative in nature and tends to occur in the central avascular region.

(Reprinted with permission from [154])
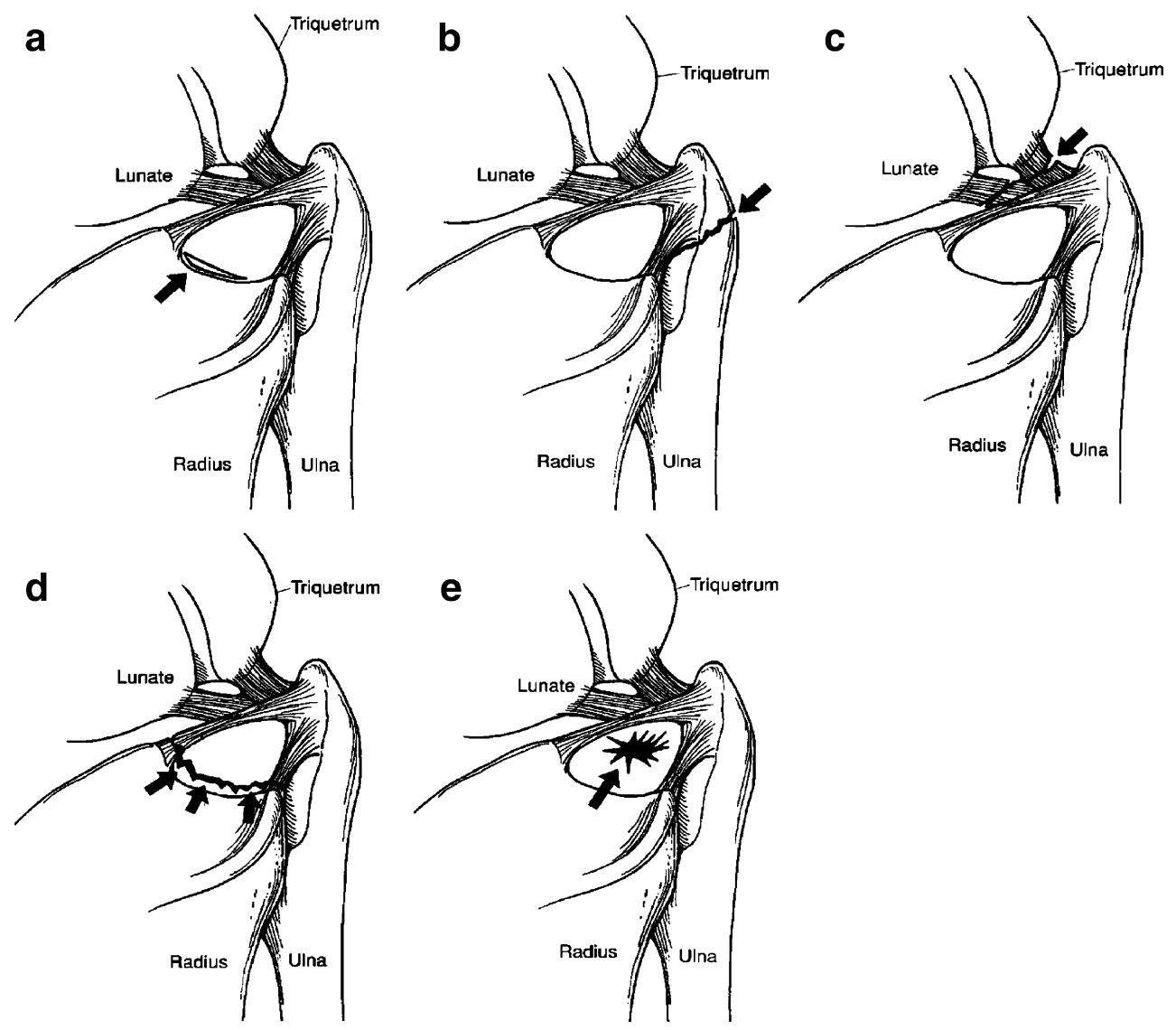

styloid process fracture [102]. An ulnar styloid is considered long when its overall length is greater than $6 \mathrm{~mm}$ or when the ulnar styloid process index, which is defined as (styloid length - ulnar variance)/width of the ulnar head [113], is greater than 0.12 [114]. Radiography may also demonstrate subchondral changes that may include sclerosis or cystic changes in the proximal triquetrum.

Magnetic imaging reveals a long styloid or ununited bone fragment of styloid process and may show secondary changes of ulnar styloid impaction syndrome, such as degeneration or defect of cartilage, marrow edema, sub-

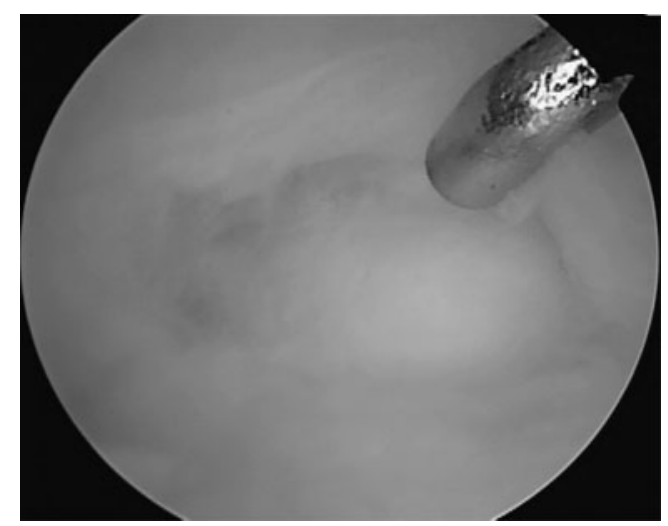

Fig. 15 Arthroscopic image through a TFCC lesion on the distal

aspect of the ulna A radiograph may demonstrate a long ulnar styloid
process, a volar or radial curved ulnar styloid, or a nonunited A radiograph may demonstrate a long ulnar styloid
process, a volar or radial curved ulnar styloid, or a nonunited
Ulnar styloid impaction syndrome Ulnar styloid impaction syndrome, which occurs less frequently than ulnar impaction syndrome, is caused by the impaction between the ulnar styloid and the proximal triquetrum and more commonly develops in wrists with negative ulnar variance [111]. The ulnar styloid process is a continuation of the prominent subcutaneous ridge of the shaft of the ulna, which projects distally toward the triquetral bone for a variable distance $(2-6 \mathrm{~mm})$ [112]. Typical imaging findings for the ulnar styloid impingement syndrome are explained next. 


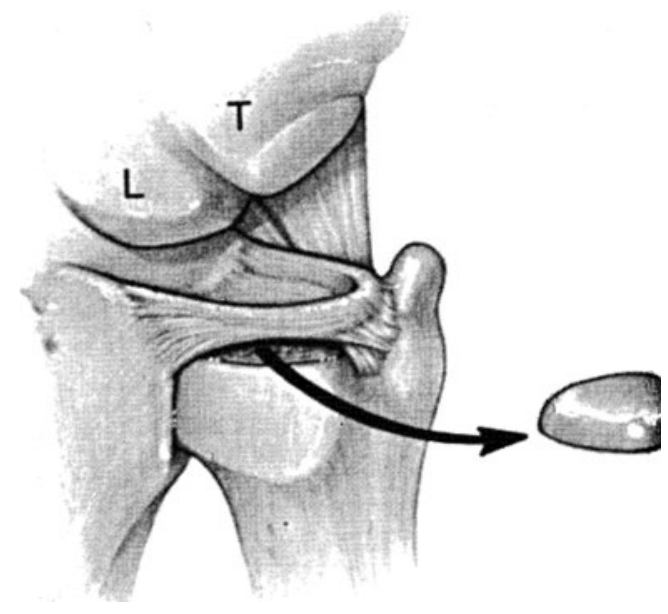

Fig. 16 Ulnar shortening osteotomy. This procedure is performed for positive ulnar variance to relieve ulnar impaction. This can be accomplished by extra-articular ulnar shortening osteotomy or an arthroscopic intra-articular wafer resection. (Reprinted with permission from [152])

chondral cysts, sclerotic changes of the proximal triquetrum, and ulnar styloid [62]. MR arthrography can aid in the evaluation of the TFCC injury, which is often associated with ulnar styloid impaction syndrome [115].

\section{Treatment}

Extensor carpi ulnaris tendonitis

Extensor carpi ulnaris tendonitis is often encountered in patients who perform repetitive extensor movements of the wrist. Conservative management for ECU tendonitis consists of wrist immobilization in the slight flexion and radial deviation [116]. Athletes who experience ECU tendonitis often benefit from activity and equipment modifications as well as improved athletic conditioning [116, 117]. Corticosteroid injections are also used in patients for whom the former measures are insufficient. Most patients will respond to these conservative measures, hence surgical treatment is unusual. Indications for surgical intervention include failure of conservative treatment, young active patients with ECU subluxation (which presents with ulnar-sided wrist pain and "popping" as the tendon slides ulnarly out of the ECU groove), and partial or complete ruptures of the ECU tendon [118]. The most common surgical treatment consists of reconstruction of the ECU subsheath using the adjacent extensor retinaculum (Fig. 12) [63, 118-121]. The forearm is immobilized for 6 weeks postoperatively following ECU subsheath reconstruction.

Flexor carpi ulnaris tendonitis

Like ECU tendonitis, FCU tendonitis occurs on the ulnar aspect of the wrist with repetitive motions. FCU tendonitis occurs with repetitive flexion, and it can be subdivided into calcific or non-calcific etiologies [67, 122-124]. Examination reveals pain with resisted flexion and ulnar deviation. In contrast to pisotriquetral arthritis (discussed later), the pain caused by FCU tendonitis is elicited approximately $3 \mathrm{~cm}$ proximal to the pisiform along the palpable tendon instead of at the pisotriquetral joint [67]. Conservative management consists of splint immobilization, anti-inflammatory medications, and physical therapy that includes strengthening and
Fig. 17 Hemiresection arthroplasty of the distal ulna with soft tissue interposition. a The fifth extensor compartment of the distal radioulnar joint $(D R U J)$ is opened, and a dorsal flap of the extensor retinaculum and dorsal DRUJ capsule is elevated. The radial aspect of the distal ulna is resected obliquely and shaped with a burr. b The ulnar edges of the flap of the extensor retinaculum and dorsal DRUJ capsule are sutured to the volar DRUJ capsule. c Axial depiction of the completed hemiresection arthroplasty. (Reprinted with permission from [152])

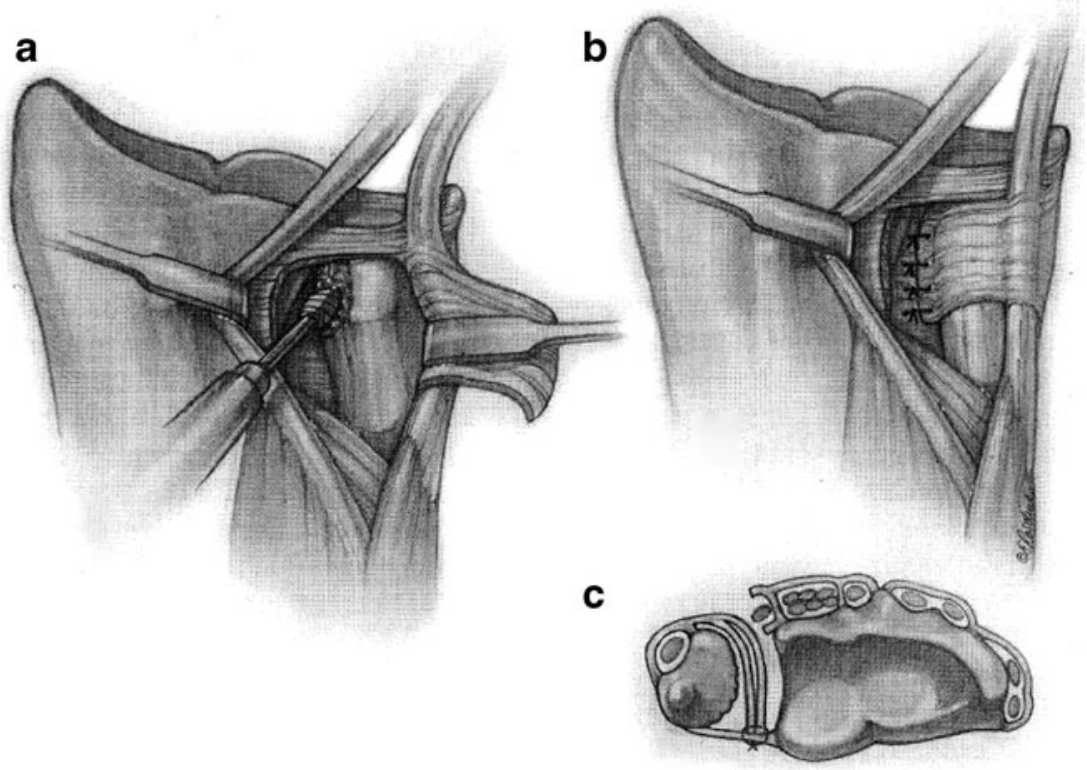




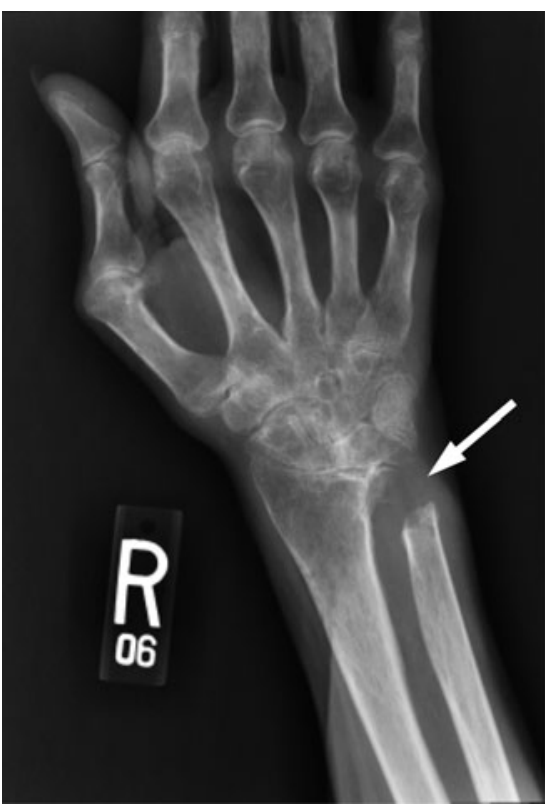

Fig. 18 Posteroanterior radiograph of a patient with rheumatoid arthritis treated with the Darrach procedure (distal ulna resection)

stretching exercises. Occasionally, steroid injections may be utilized [122]. FCU tendonitis usually responds successfully to conservative measures. Surgical options for failure of conservative therapy include FCU tendon lengthening and FCU tendon debridement [67]. A small study of FCU tendon debridement demonstrated an excellent outcome. Five wrists treated surgically in four patients were evaluated at a minimum of 1 year postoperatively, with the average followup of 20 months. All patients reported complete or nearcomplete relief of their symptoms [67].

\section{Pisotriquetral arthritis}

Pisotriquetral arthritis is a common arthritic cause of ulnar-sided wrist pain. Most cases respond to conservative management with splint immobilization and antiinflammatory medications. On examination, tenderness with direct pressure over the pisiform is found. A positive pisotriquetral shear test confirms the diagnosis. This maneuver is performed by translating the pisiform radially and ulnarly while applying dorsally directed pressure. Diagnosis is made if the patient's symptoms reoccur. Another confirmatory maneuver, which has therapeutic benefit as well, is corticosteroid injection. Pain relief with local lidocaine and/or steroid injection is typical, although it may be temporary [61]. Subperiosteal excision of the pisiform is an effective surgical management option if nonsurgical management fails [125-129]. At surgery the FCU tendon is split longitudinally over the pisiform. which is completely excised. Then, the longitudinal split is repaired. When performing this surgical procedure it is important to protect the ulnar artery and nerve as well as the FCU tendon $[61,125]$.

Triangular fibrocartilage complex lesions and ulnar impaction

Triangular fibrocartilage complex provides stability to the DRUJ and may be damaged by trauma or repetitive movements (Fig. 13). Pathology of the TFCC can be classified into two types (Table 1) [130, 131]. Type I lesions are traumatic in etiology, often resulting from a fall on the outstretched hand, producing an axial loading force or hyperpronation injury to the forearm (Fig. 14). These tears are more common (in contrast to degenerative lesions) at the periphery of the TFCC, which is the vascular zone of the complex [132]. Type I tears are further subdivided into types IA through ID. Type IA tears are the most common and are located within the avascular articular disk. The articular disk has limited healing capacity; thus, arthroscopic debridement is the surgical treatment of choice (Fig. 15) [130]. Types IB and IC tears are within the peripheral vascular zone of the TFCC, and open repair of these lesions has been performed with good results [133, 134]. Arthroscopic repair of peripheral tears with or without ulnar shortening osteotomy is another viable option for peripheral lesions $[61,135,136]$. Nonsurgical management includes immobilization, anti-inflammatory medications, and steroid injection. Several surgical options may be considered if conservative measures do not provide full relief of the patient's symptoms. Surgical treatment is based upon the location of the TFCC lesion; typically, if the lesion is within the vascular zone of the TFCC, traumatic
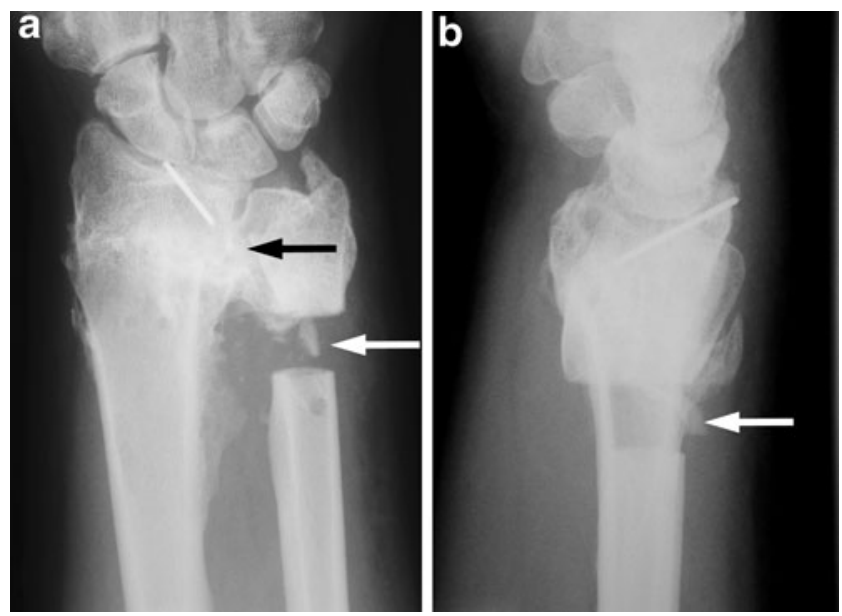

Fig. 19 Sauvé-Kapandji procedure. a Posteroanterior and b lateral radiographs of a patient treated with the Sauvé-Kapandji procedure. Black arrow depicts the successful DRUJ fusion. White arrows depict the resected area of the distal ulnar shaft that preserves forearm rotation 

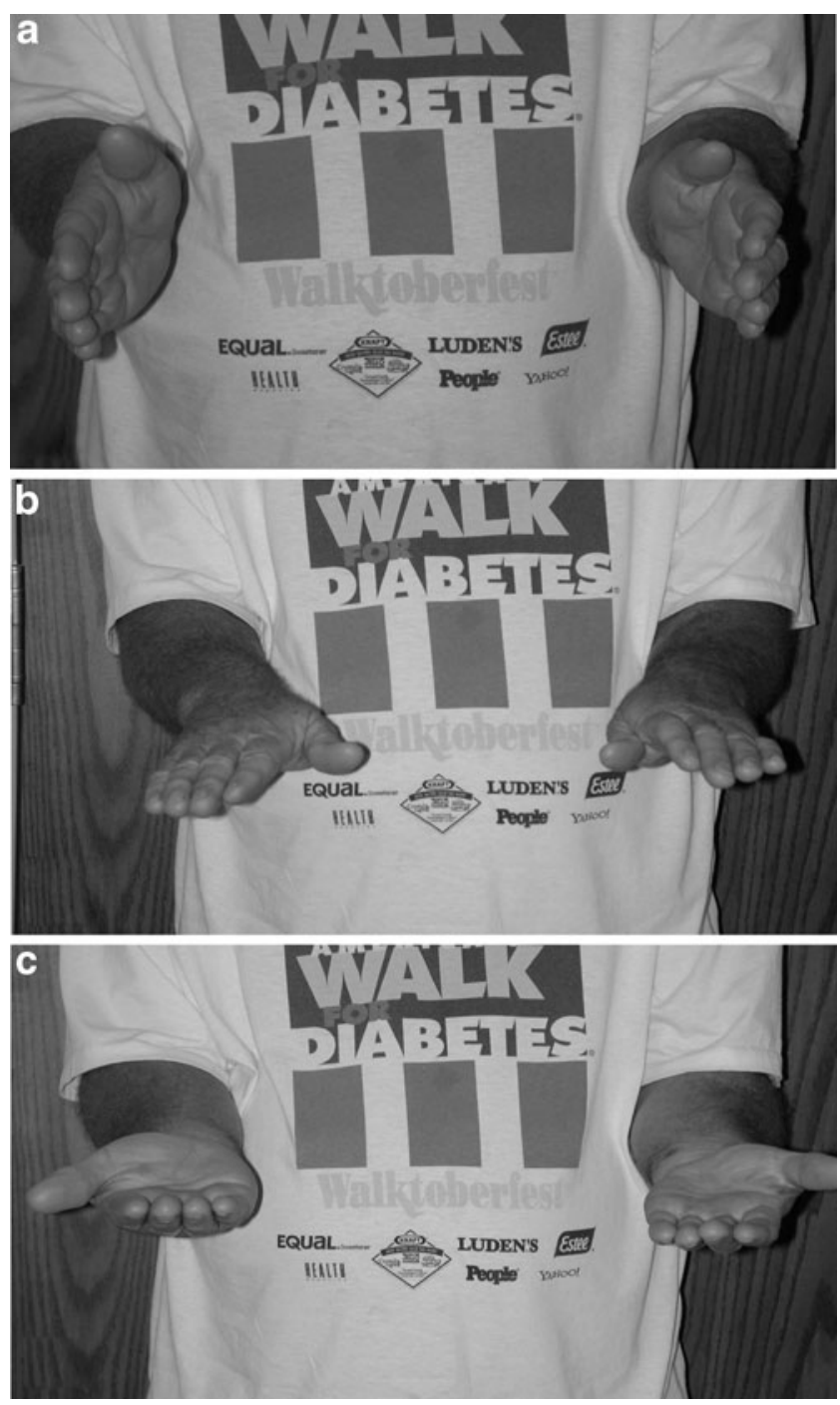

Fig. 20 Photographs of a patient treated with the Sauvé-Kapandji procedure demonstrate the preservation of forearm rotation afforded by this operation. Forearm in a neutral rotation, b $90^{\circ}$ of pronation, and $\mathbf{c} 90^{\circ}$ of supination

lesions are repaired. Lesions in the avascular zone are most typically debrided.

Type II TFCC tears are generally atraumatic, degenerative injuries secondary to ulnar impaction syndrome [103], or repetitive loading (Fig. 14). Type II tears are usually in the central avascular region of the articular disk, and they are further subdivided into types IIA through IIE (Table 1). These subtypes are based on the progressive destruction of the TFCC and adjacent ligaments and cartilage and range from partial thickness lesions of the articular disk (IIA) to full thickness lesions with arthrosis and disruption of the lunotriquetral articulation (IIE). Conservative management and indications for surgical intervention are similar to those described for type I TFCC tears. Surgical treatment options differ for type II tears because of the different location of the tears and thus have poorer healing potential. Arthro- scopic debridement is the mainstay of treatment for central type II TFCC tears (Fig. 15) [61, 135]. Rehabilitation is initiated after 2 weeks of immobilization postoperatively. Often, patients with type II TFCC tears patients have positive ulnar variance, or increased length of the ulna compared with the radius causing the ulnar impaction. An ulnar shortening procedure should be performed for positive ulnar variance to relieve ulnar impaction (Fig. 16). This can be accomplished by extra-articular ulnar shortening osteotomy or an arthroscopic intra-articular wafer resection of the ulna to correct the disparity between the lengths of the radius and ulna [137-139]. These techniques were recently compared in a series of 22 patients. Both methods provided good or excellent results; however, patients who underwent ulnar shortening osteotomy had higher risks of nonunion and occasionally required hardware removal [140]. Currently, many surgeons make their choice based on individual experience and training as there is not a consensus in the literature [140]. Type IIE tears are the most severe type II TFCC injuries and can require salvage procedures such as the Bowers (hemiresection arthroplasty of the distal ulna with tendon interposition; Fig. 17), Darrach (distal ulna resection; Fig. 18), or SauvéKapandji procedures (DRUJ fusion with resection of a portion of the distal ulnar shaft to preserve forearm rotation; Figs. 19, 20) [130, 141].

While positive ulnar variance may be implicated in the development of TFCC tears and impacts the treatment of these tears, isolated positive ulnar variance may lead to ulnar impaction syndrome impingement with less overt damage to the TFCC. Ulnar impaction syndrome occurs when the ulna causes painful compression against the proximal lunate and triquetrum. The surgical treatment of ulnar impaction syndrome parallels the treatment of
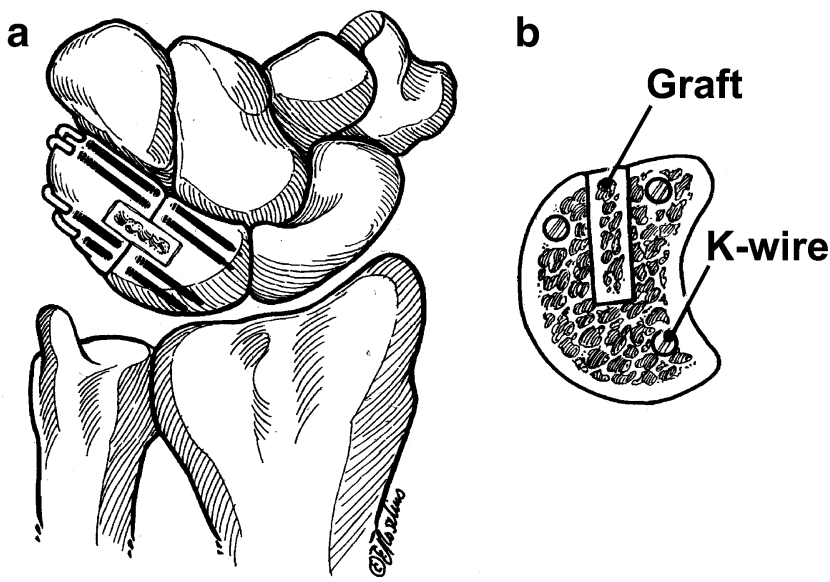

Fig. 21 Lunotriquetral $(L T)$ arthrodesis is indicated for LT tears that are unresponsive to arthroscopic debridement. a Posteroanterior plane of LT arthrodesis. b Sagittal oblique plane through the LT arthrodesis site demonstrating correct placement of bone graft and K-wires. (Reprinted with permission from [152]) 
positive ulnar variance in association with TFCC pathology, including ulnar shortening osteotomy and arthroscopic wafer ulnar resection [142].

\section{Lunotriquetral instability}

Lunotriquetral (LT) instability is another common cause of ulnar-sided wrist pathology. The LT ligament is an important intrinsic ligament of the proximal carpal row. Damage to this ligament may be the result of several possible mechanisms of injury. One such mechanism is a fall on the outstretched hand in pronation, extension, and radial deviation [143]. The first step in management of acute LT ligament injuries is immobilization in a cast or splint [143]. Steroid injection is often helpful in the diagnosis and symptomatic relief of LT ligament injuries, particularly with delayed presentation [79]. Conservative management of this pathology is usually successful [61].

Indications for surgical treatment are controversial, but include failure of conservative therapy or VISI deformity $[79,143]$. The goal of surgical management is to reestablish the lunocapitate alignment and to restore the integrity of the proximal carpal row [79]. A number of surgical options exist in the treatment of LT ligament injuries. Arthroscopic LT debridement alone has been demonstrated to provide effective symptomatic relief [144]. Open LT ligament repair entails re-approximation of the LT ligament-most commonly the ligament has ruptured from the triquetrum - and repair of the volar ligament if it has been disrupted. Unfortunately, the senior author's experience has been that there is rarely sufficient tissue for effective repair. Open ligamentous repair requires a significant period of immobilization postoperatively $[143,145]$. LT ligament reconstruction is another surgical option that is recommended by some authors if chronic LT instability exists or if a strong construct is required because of high demands placed on the wrist. In this procedure a portion of the ECU tendon can be used to reconstruct the LT ligament [143, 145]. In addition to LT ligament debridement, repair, or reconstruction, positive ulnar variance must be addressed with an ulnar shortening procedure if it exists [79, 143, 146].

When traditional LT ligamentous surgical options fail to relieve symptoms or are contraindicated, several salvage procedures exist. LT arthrodesis is a surgical option for LT tears that are unresponsive to arthroscopic debridement (Fig. 21) [147]. Midcarpal arthrodesis is indicated for patients with LT instability associated with midcarpal instability as demonstrated by the finding of a midcarpal clunk with longitudinal wrist compression and radial and ulnar deviation. Trumble et al. recommend fusion of the capitate, lunate, triquetrum, and hamate (so called "fourcorner fusion") when performing midcarpal arthrodesis for LT instability that coexists with midcarpal instability [147].
Proximal row carpectomy is an alternative to arthrodesis in which the scaphoid, lunate, and triquetrum are excised, leaving the proximal pole of the capitate to articulate with the distal radius [79]. Finally, total wrist arthrodesis may be used to successfully treat LT instability, particularly if degenerative changes make other salvage procedures less attractive [79].

\section{Distal radioulnar joint instability}

Distal radioulnar joint instability is another etiology of ulnarsided wrist pain that is commonly encountered in clinical practice. DRUJ instability may occur in the presence or absence of DRUJ arthritis. Conservative management of an acute DRUJ injury or dislocation consists of closed reduction followed by immobilization. Dorsal DRUJ dislocation requires immobilization in a position of supination for 4 weeks post-reduction, whereas volar DRUJ dislocation requires immobilization in pronation. Surgical treatment is indicated for chronic DRUJ dislocation or failure of closed reduction. This consists of open reduction and pinning of the DRUJ in neutral rotation and immobilization [148]. In some cases a tendon graft reconstruction of the DRUJ ligamentous supports, as described by Adams, is indicated [149]. Chronic DRUJ instability occasionally requires more extensive or salvage-type surgical treatment, particularly when associated arthrosis is established. Surgical options include those described previously for DRUJ arthrosis including Bowers, Darrach or Sauvé-Kapandji procedures (Figs. 17-19) $[141,150]$.

Open Access This article is distributed under the terms of the Creative Commons Attribution Noncommercial License which permits any noncommercial use, distribution, and reproduction in any medium, provided the original author(s) and source are credited.

\section{References}

1. Goldfarb CA, Yin Y, Gilula LA, Fisher AJ, Boyer MI. Wrist fractures: what the clinician wants to know. Radiology. 2001; 219(1):11-28.

2. Heuck A, Bonel H, Stabler A, Schmitt R. Imaging in sports medicine: hand and wrist. Eur J Radiol. 1997;26(1):2-15.

3. Loredo RA, Sorge DG, Garcia G. Radiographic evaluation of the wrist: a vanishing art. Semin Roentgenol. 2005;40(3):248-89.

4. Chung KC, Zimmerman NB, Travis MT. Wrist arthrography versus arthroscopy: a comparative study of 150 cases. J Hand Surg [Am]. 1996;21(4):591-4.

5. Mikic ZD. Arthrography of the wrist joint. An experimental study. J Bone Joint Surg Am. 1984;66(3):371-8.

6. Hugo PC III, Newberg AH, Newman JS, Wetzner SM. Complications of arthrography. Semin Musculoskelet Radiol. 1998;2(4):345-8.

7. Wong DC, Wansaicheong GK, Tsou IY. Ultrasonography of the hand and wrist. Singapore Med J. 2009;50(2):219-25; quiz 226. 
8. Bajaj S, Pattamapaspong N, Middleton W, Teefey S. Ultrasound of the hand and wrist. J Hand Surg Am. 2009;34(4):759-60.

9. Lee KS, Ablove RH, Singh S, De Smet AA, Haaland B, Fine JP. Ultrasound imaging of normal displacement of the extensor carpi ulnaris tendon within the ulnar groove in 12 forearm-wrist positions. AJR Am J Roentgenol. 2009;193(3):651-5.

10. Bianchi S, Martinoli C, Abdelwahab IF. High-frequency ultrasound examination of the wrist and hand. Skeletal Radiol. 1999;28(3):121-9.

11. Fornage BD, Rifkin MD. Ultrasound examination of the hand and foot. Radiol Clin North Am. 1988;26(1):109-29.

12. Van Holsbeeck M, Introcaso JH. Musculoskeletal ultrasonography. Radiol Clin North Am. 1992;30(5):907-25.

13. Kaewlai R, Avery LL, Asrani AV, Abujudeh HH, Sacknoff R, Novelline RA. Multidetector CT of carpal injuries: anatomy, fractures, and fracture-dislocations. Radiographics. 2008;28 (6): 1771-84.

14. Omlor G, Jung M, Grieser T, Ludwig K. Depiction of the triangular fibro-cartilage in patients with ulnar-sided wrist pain: comparison of direct multi-slice CT arthrography and direct MR arthrography. Eur Radiol. 2009;19(1):147-51.

15. Bille B, Harley B, Cohen H. A comparison of CT arthrography of the wrist to findings during wrist arthroscopy. J Hand Surg [Am]. 2007;32(6):834-41.

16. Moser T, Dosch JC, Moussaoui A, Buy X, Gangi A, Dietemann JL. Multidetector CT arthrography of the wrist joint: how to do it. Radiographics. 2008;28(3):787-800; quiz 911.

17. Theumann N, Favarger N, Schnyder P, Meuli R. Wrist ligament injuries: value of post-arthrography computed tomography. Skeletal Radiol. 2001;30(2):88-93.

18. Daunt N. Magnetic resonance imaging of the wrist: anatomy and pathology of interosseous ligaments and the triangular fibrocartilage complex. Curr Probl Diagn Radiol. 2002;31(4):158-76.

19. Horton MG, Timins ME. MR imaging of injuries to the small joints. Radiol Clin North Am. 1997;35(3):671-700.

20. Imaeda $T$, Nakamura R, Shionoya K, Makino N. Ulnar impaction syndrome: MR imaging findings. Radiology. 1996;201(2):495-500.

21. Oneson SR, Scales LM, Timins ME, Erickson SJ, Chamoy L. MR imaging interpretation of the Palmer classification of triangular fibrocartilage complex lesions. Radiographics. 1996;16(1):97-106.

22. Totterman SM, Miller R, Wasserman B, Blebea JS, Rubens DJ. Intrinsic and extrinsic carpal ligaments: evaluation by threedimensional Fourier transform MR imaging. AJR Am J Roentgenol. 1993;160(1):117-23.

23. Ashman CJ, Farooki S, Abduljalil AM, Chakeres DW. In vivo high resolution coronal MRI of the wrist at 8.0 tesla. J Comput Assist Tomogr. 2002;26(3):387-91.

24. Yoshioka H, Ueno T, Tanaka T, Shindo M, Itai Y. Highresolution MR imaging of triangular fibrocartilage complex (TFCC): comparison of microscopy coils and a conventional small surface coil. Skeletal Radiol. 2003;32(10):575-81.

25. Lewis AR, Nolan MJ, Hodgson RJ, Benjamin M, Ralphs JR, Archer $\mathrm{CW}$, et al. High resolution magnetic resonance imaging of the proximal interphalangeal joints. Correlation with histology and production of a three-dimensional data set. J Hand Surg [Br]. 1996;21(4):488-95.

26. Bittersohl B, Huang T, Schneider E, Blazar P, Winalski C, Lang $\mathrm{P}$, et al. High-resolution MRI of the triangular fibrocartilage complex (TFCC) at 3T: comparison of surface coil and volume coil. J Magn Reson Imaging. 2007;26(3):701-7.

27. Anderson ML, Skinner JA, Felmlee JP, Berger RA, Amrami KK. Diagnostic comparison of 1.5 Tesla and 3.0 Tesla preoperative MRI of the wrist in patients with ulnar-sided wrist pain. J Hand Surg Am. 2008;33(7):1153-9.
28. Steinbach LS, Palmer WE, Schweitzer ME. Special focus session. MR arthrography. Radiographics. 2002;22(5):1223-46.

29. Scheck RJ, Kubitzek C, Hierner R, Szeimies U, Pfluger T, Wilhelm K, et al. The scapholunate interosseous ligament in MR arthrography of the wrist: correlation with non-enhanced MRI and wrist arthroscopy. Skeletal Radiol. 1997;26(5):263-71.

30. Bergin D, Schweitzer ME. Indirect magnetic resonance arthrography. Skeletal Radiol. 2003;32(10):551-8.

31. Schweitzer ME, Natale P, Winalski CS, Culp R. Indirect wrist MR arthrography: the effects of passive motion versus active exercise. Skeletal Radiol. 2000;29(1):10-4.

32. Haims AH, Schweitzer ME, Morrison WB, Deely D, Lange RC, Osterman $\mathrm{AL}$, et al. Internal derangement of the wrist: indirect MR arthrography versus unenhanced MR imaging. Radiology. 2003;227(3):701-7.

33. Knirk JL, Jupiter JB. Intra-articular fractures of the distal end of the radius in young adults. J Bone Joint Surg Am. 1986;68(5): 647-59.

34. Hauck RM, Skahen J III, Palmer AK. Classification and treatment of ulnar styloid nonunion. J Hand Surg [Am]. 1996;21(3):418-22.

35. Papp S. Carpal bone fractures. Orthop Clin North Am. 2007;38 (2):251-60. vii.

36. Foucher G, Schuind F, Merle M, Brunelli F. Fractures of the hook of the hamate. J Hand Surg [Br]. 1985;10(2):205-10.

37. Welling RD, Jacobson JA, Jamadar DA, Chong S, Caoili EM, Jebson PJ. MDCT and radiography of wrist fractures: radiographic sensitivity and fracture patterns. AJR Am J Roentgenol. 2008;190(1):10-6.

38. Goedkoop AY, van Onselen EB, Karim RB, Hage JJ. The 'mirrored' Bennett fracture of the base of the fifth metacarpal. Arch Orthop Trauma Surg. 2000;120(10):592-3.

39. Fleege MA, Jebson PJ, Renfrew DL, el-Khoury GY, Steyers CM Jr. Pisiform fractures. Skeletal Radiol. 1991;20(3):169-72.

40. Zimmerman NB, Mass DP. A pisiform fracture. Orthopedics. 1987;10(5):817-20.

41. Dalinka MK, Merrill C. Sosman lecture. MR imaging of the wrist. AJR Am J Roentgenol. 1995;164(1):1-9.

42. Hooper G. Kienbock's disease. J Hand Surg [Br]. 1992;17(1):34.

43. Gelberman RH, Salamon PB, Jurist JM, Posch JL. Ulnar variance in Kienbock's disease. J Bone Joint Surg Am. 1975;57 (5):674-6.

44. Nathan PA, Meadows KD. Ulna-minus variance and Kienbock's disease. J Hand Surg [Am]. 1987;12(5 Pt 1):777-778.

45. Schuind F, Eslami S, Ledoux P. Kienbock's disease. J Bone Joint Surg Br. 2008;90(2):133-9.

46. Amadio PC, Hanssen AD, Berquist TH. The genesis of Kienbock's disease: evaluation of a case by magnetic resonance imaging. J Hand Surg [Am]. 1987;12(6):1044-9.

47. Lichtman DM, Alexander AH, Mack GR, Gunther SF. Kienbock's disease - update on silicone replacement arthroplasty. J Hand Surg [Am]. 1982;7(4):343-7.

48. Stoller DW. The wrist. Semin Roentgenol. 1995;30(3):265-76.

49. Desser TS, McCarthy S, Trumble T. Scaphoid fractures and Kienbock's disease of the lunate: MR imaging with histopathologic correlation. Magn Reson Imaging. 1990;8(4):357-61.

50. Cooney WP. Evaluation of chronic wrist pain by arthrography, arthroscopy, and arthrotomy. J Hand Surg [Am]. 1993;18(5): $815-22$.

51. Schweitzer ME, Brahme SK, Hodler J, Hanker GJ, Lynch TP, Flannigan BD, et al. Chronic wrist pain: spin-echo and short tau inversion recovery MR imaging and conventional and MR arthrography. Radiology. 1992;182(1):205-11.

52. Totterman SM, Miller RJ. Triangular fibrocartilage complex: normal appearance on coronal three-dimensional gradientrecalled-echo MR images. Radiology. 1995;195(2):521-7. 
53. Totterman SM, Miller RJ, McCance SE, Meyers SP. Lesions of the triangular fibrocartilage complex: MR findings with a threedimensional gradient-recalled-echo sequence. Radiology. 1996;199(1):227-32.

54. Potter HG, Asnis-Ernberg L, Weiland AJ, Hotchkiss RN, Peterson MG, McCormack RR Jr. The utility of high-resolution magnetic resonance imaging in the evaluation of the triangular fibrocartilage complex of the wrist. J Bone Joint Surg Am. 1997;79(11):1675-84.

55. Oneson SR, Timins ME, Scales LM, Erickson SJ, Chamoy L. MR imaging diagnosis of triangular fibrocartilage pathology with arthroscopic correlation. AJR Am J Roentgenol. 1997;168 (6):1513-8.

56. Tanaka $\mathrm{T}$, Yoshioka $\mathrm{H}$, Ueno $\mathrm{T}$, Shindo $\mathrm{M}$, Ochiai $\mathrm{N}$. Comparison between high-resolution MRI with a microscopy coil and arthroscopy in triangular fibrocartilage complex injury. J Hand Surg [Am]. 2006;31(8):1308-14.

57. Zanetti M, Linkous MD, Gilula LA, Hodler J. Characteristics of triangular fibrocartilage defects in symptomatic and contralateral asymptomatic wrists. Radiology. 2000;216(3):840-5.

58. Finlay K, Lee R, Friedman L. Ultrasound of intrinsic wrist ligament and triangular fibrocartilage injuries. Skeletal Radiol. 2004;33(2):85-90.

59. Chiou HJ, Chang CY, Chou YH, Hsu CC, Jim YF, Tiu CM, et al. Triangular fibrocartilage of wrist: presentation on high resolution ultrasonography. J Ultrasound Med. 1998;17(1):41-8.

60. Keogh CF, Wong AD, Wells NJ, Barbarie JE, Cooperberg PL. High-resolution sonography of the triangular fibrocartilage: initial experience and correlation with MRI and arthroscopic findings. AJR Am J Roentgenol. 2004;182(2):333-6.

61. Buterbaugh GA, Brown TR, Horn PC. Ulnar-sided wrist pain in athletes. Clin Sports Med. 1998;17(3):567-83.

62. Coggins CA. Imaging of ulnar-sided wrist pain. Clin Sports Med. 2006;25(3):505-26. vii.

63. Eckhardt WA, Palmer AK. Recurrent dislocation of extensor carpi ulnaris tendon. J Hand Surg [Am]. 1981;6(6):629-31.

64. MacLennan AJ, Nemechek NM, Waitayawinyu T, Trumble TE. Diagnosis and anatomic reconstruction of extensor carpi ulnaris subluxation. J Hand Surg [Am]. 2008;33(1):59-64.

65. Pratt RK, Hoy GA, Bass Franzcr C. Extensor carpi ulnaris subluxation or dislocation? Ultrasound measurement of tendon excursion and normal values. Hand Surg. 2004;9(2):13743.

66. Hajj AA, Wood MB. Stenosing tenosynovitis of the extensor carpi ulnaris. J Hand Surg [Am]. 1986;11(4):519-20.

67. Budoff JE, Kraushaar BS, Ayala G. Flexor carpi ulnaris tendinopathy. J Hand Surg [Am]. 2005;30(1):125-9.

68. Zeiss J, Jakab E, Khimji T, Imbriglia J. The ulnar tunnel at the wrist (Guyon's canal): normal MR anatomy and variants. AJR Am J Roentgenol. 1992;158(5):1081-5.

69. Murata K, Shih JT, Tsai TM. Causes of ulnar tunnel syndrome: a retrospective study of 31 subjects. J Hand Surg [Am]. 2003; 28(4):647-51.

70. Bordalo-Rodrigues M, Amin P, Rosenberg ZS. MR imaging of common entrapment neuropathies at the wrist. Magn Reson Imaging Clin N Am. 2004;12(2):265-79. vi.

71. McAlinden P, The J. Imaging of the wrist. Imaging. 2003;15: 180-92.

72. Stark HH, Chao EK, Zemel NP, Rickard TA, Ashworth CR. Fracture of the hook of the hamate. J Bone Joint Surg Am. 1989;71(8):1202-7.

73. Giuliani G, Poppi M, Pozzati E, Forti A. Ulnar neuropathy due to a carpal ganglion: the diagnostic contribution of CT. Neurology. 1990;40(6): 1001-2.

74. Steinbach LS, Smith DK. MRI of the wrist. Clin Imaging. 2000;24(5):298-322.
75. Timins ME, Jahnke JP, Krah SF, Erickson SJ, Carrera GF. MR imaging of the major carpal stabilizing ligaments: normal anatomy and clinical examples. Radiographics. 1995;15(3):575-87.

76. Palmer AK. Triangular fibrocartilage complex lesions: a classification. J Hand Surg [Am]. 1989;14(4):594-606.

77. Van Schoonhoven J, Prommersberger KJ, Schmitt R. Traumatic disruption of a fibrocartilage lunate-triquetral coalition - a case report and review of the literature. Hand Surg. 2001;6(1): $103-8$.

78. Kirschenbaum D, Coyle MP, Leddy JP. Chronic lunotriquetral instability: diagnosis and treatment. J Hand Surg [Am]. 1993;18 (6):1107-12.

79. Shin AY, Battaglia MJ, Bishop AT. Lunotriquetral instability: diagnosis and treatment. J Am Acad Orthop Surg. 2000;8(3):170-9.

80. Schmid MR, Schertler T, Pfirrmann CW, Saupe N, Manestar M, Wildermuth $\mathrm{S}$, et al. Interosseous ligament tears of the wrist: comparison of multi-detector row CT arthrography and MR imaging. Radiology. 2005;237(3):1008-13.

81. Yoshioka H, Ueno T, Tanaka T, Shindo M, Lang P. Highresolution MR imaging of the intercarpal ligaments with a microscopy coil. In: RSNA 90th Scientific Assembly and Annual Meeting. 2004.

82. Manton GL, Schweitzer ME, Weishaupt D, Morrison WB, Osterman AL, Culp RW, et al. Partial interosseous ligament tears of the wrist: difficulty in utilizing either primary or secondary MRI signs. J Comput Assist Tomogr. 2001;25(5):671-6.

83. Zlatkin MB, Rosner J. MR imaging of ligaments and triangular fibrocartilage complex of the wrist. Magn Reson Imaging Clin N Am. 2004;12(2):301-31. vi-vii.

84. Brown DE, Lichtman DM. Midcarpal instability. Hand Clin. 1987;3(1):135-40.

85. Lichtman DM, Bruckner JD, Culp RW, Alexander CE. Palmar midcarpal instability: results of surgical reconstruction. J Hand Surg [Am]. 1993;18(2):307-15.

86. Lichtman DM, Wroten ES. Understanding midcarpal instability. J Hand Surg [Am]. 2006;31(3):491-8.

87. Chang W, Peduto AJ, Aguiar RO, Trudell DJ, Resnick DL. Arcuate ligament of the wrist: normal MR appearance and its relationship to palmar midcarpal instability: a cadaveric study. Skeletal Radiol. 2007;36(7):641-5.

88. Rominger MB, Bernreuter WK, Kenney PJ, Lee DH. MR imaging of anatomy and tears of wrist ligaments. Radiographics. 1993;13(6):1233-46; discussion 1247-1238.

89. Brody G. The wrist and hand. In: Stoller D, editor. Magnetic resonance imaging in orthopedics and sports medicine. Philadelphia: Lippincott; 1993. p. 683-807.

90. Szabo RM. Distal radioulnar joint instability. J Bone Joint Surg Am. 2006;88(4):884-94.

91. Kihara H, Palmer AK, Werner FW, Short WH, Fortino MD. The effect of dorsally angulated distal radius fractures on distal radioulnar joint congruency and forearm rotation. J Hand Surg [Am]. 1996;21(1):40-7.

92. Epner RA, Bowers WH, Guilford WB. Ulnar variance- the effect of wrist positioning and roentgen filming technique. J Hand Surg [Am]. 1982;7(3):298-305.

93. Mino DE, Palmer AK, Levinsohn EM. Radiography and computerized tomography in the diagnosis of incongruity of the distal radio-ulnar joint. A prospective study. J Bone Joint Surg Am. 1985;67(2):247-52.

94. Cone RO, Szabo R, Resnick D, Gelberman R, Taleisnik J, Gilula LA. Computed tomography of the normal radioulnar joints. Invest Radiol. 1983;18(6):541-5.

95. King GJ, McMurtry RY, Rubenstein JD, Ogston NG. Computerized tomography of the distal radioulnar joint: correlation with ligamentous pathology in a cadaveric model. J Hand Surg [Am]. 1986;11(5):711-7. 
96. Arora AS, Chung KC, Otto W. Madelung and the recognition of Madelung's deformity. J Hand Surg [Am]. 2006;31(2):177-82.

97. Zebala LP, Manske PR, Goldfarb CA. Madelung's deformity: a spectrum of presentation. J Hand Surg [Am]. 2007;32(9):1393-401.

98. McCarroll HR Jr, James MA, Newmeyer WL II, Molitor F, Manske PR. Madelung's deformity: quantitative assessment of $\mathrm{x}$ ray deformity. J Hand Surg [Am]. 2005;30(6):1211-20.

99. Bell MJ, Hill RJ, McMurtry RY. Ulnar impingement syndrome. J Bone Joint Surg Br. 1985;67(1):126-9.

100. Cerezal L, del Pinal F, Abascal F, Garcia-Valtuille R, Pereda T, Canga A. Imaging findings in ulnar-sided wrist impaction syndromes. Radiographics. 2002;22(1):105-21.

101. Lees V, Scheker L. The radiological demonstration of dynamic ulnar impingement. J Hand Surg [Br]. 1997;22B(4):448-50.

102. Cerezal L, del Pinal F, Abascal F. MR imaging findings in ulnarsided wrist impaction syndromes. Magn Reson Imaging Clin N Am. 2004;12(2):281-99. vi.

103. Friedman SL, Palmer AK. The ulnar impaction syndrome. Hand Clin. 1991;7(2):295-310.

104. Tomaino MM. Ulnar impaction syndrome in the ulnar negative and neutral wrist. Diagnosis and pathoanatomy. J Hand Surg [Br]. 1998;23(6):754-7.

105. Escobedo EM, Bergman AG, Hunter JC. MR imaging of ulnar impaction. Skeletal Radiol. 1995;24(2):85-90.

106. Thurston AJ, Stanley JK. Hamato-lunate impingement: an uncommon cause of ulnar-sided wrist pain. Arthroscopy. 2000;16(5):540-4.

107. Viegas SF, Wagner K, Patterson R, Peterson P. Medial (hamate) facet of the lunate. J Hand Surg [Am]. 1990;15(4):564-71.

108. Sagerman SD, Hauck RM, Palmer AK. Lunate morphology: can it be predicted with routine x-ray films? J Hand Surg [Am]. 1995;20(1):38-41.

109. Kato H, Nakamura R, Shionoya K, Makino N, Imaeda T. Does high-resolution MR imaging have better accuracy than standard MR imaging for evaluation of the triangular fibrocartilage complex? J Hand Surg [Br]. 2000;25(5):487-91.

110. Malik AM, Schweitzer ME, Culp RW, Osterman LA, Manton G. MR imaging of the type II lunate bone: frequency, extent, and associated findings. AJR Am J Roentgenol. 1999;173 (2):335-8.

111. Tomaino MM, Gainer M, Towers JD. Carpal impaction with the ulnar styloid process: treatment with partial styloid resection. J Hand Surg [Br]. 2001;26(3):252-5.

112. Biyani A, Mehara A, Bhan S. Morphological variations of the ulnar styloid process. J Hand Surg [Br]. 1990;15(3):352-4.

113. Garcia-Elias M. Soft-tissue anatomy and relationships about the distal ulna. Hand Clin. 1998;14(2):165-76.

114. Topper SM, Wood MB, Ruby LK. Ulnar styloid impaction syndrome. J Hand Surg [Am]. 1997;22(4):699-704.

115. Cerezal L, Abascal F, Garcia-Valtuille R, Del Pinal F. Wrist MR arthrography: how, why, when. Radiol Clin North Am. 2005;43 (4):709-31. viii.

116. Futami T, Itoman M. Extensor carpi ulnaris syndrome. Findings in 43 patients. Acta Orthop Scand. 1995;66(6):538-9.

117. Wood MB, Dobyns JH. Sports-related extraarticular wrist syndromes. Clin Orthop Relat Res. 1986;(202):93-102.

118. Allende C, Le Viet D. Extensor carpi ulnaris problems at the wrist-classification, surgical treatment and results. J Hand Surg [Br]. 2005;30(3):265-72.

119. Rowland SA. Acute traumatic subluxation of the extensor carpi ulnaris tendon at the wrist. J Hand Surg [Am]. 1986;11(6):809-11.

120. Burkhart SS, Wood MB, Linscheid RL. Posttraumatic recurrent subluxation of the extensor carpi ulnaris tendon. J Hand Surg [Am]. 1982;7(1):1-3.

121. Inoue G, Tamura Y. Surgical treatment for recurrent dislocation of the extensor carpi ulnaris tendon. J Hand Surg [Br]. 2001;26(6):556-9.
122. Moyer RA, Bush DC, Harrington TM. Acute calcific tendinitis of the hand and wrist: a report of 12 cases and a review of the literature. J Rheumatol. 1989;16(2):198-202.

123. Dilley DF, Tonkin MA. Acute calcific tendinitis in the hand and wrist. J Hand Surg [Br]. 1991;16(2):215-6.

124. Gandee RW, Harrison RB, Dee PM. Peritendinitis calcarea of flexor carpi ulnaris. AJR Am J Roentgenol. 1979;133(6):1139-41.

125. Carroll RE, Coyle MP Jr. Dysfunction of the pisotriquetral joint: treatment by excision of the pisiform. J Hand Surg [Am]. 1985;10(5):703-7.

126. Johnston GH, Tonkin MA. Excision of pisiform in pisotriquetral arthritis. Clin Orthop Relat Res. 1986;(210):137-142.

127. Nuesch B, Sennwald G, Segmuller G. Extirpation of the pisiform bone: indications and results. Handchir Mikrochir Plast Chir. 1993;25(1):42-5.

128. Beckers A, Koebke J. Mechanical strain at the pisotriquetral joint. Clin Anat. 1998;11(5):320-6.

129. Jenkins SA. Osteoarthritis of the pisiform-triquetral joint; report of three cases. J Bone Joint Surg Br. 1951;33B(4):532-4.

130. Ahn AK, Chang D, Plate AM. Triangular fibrocartilage complex tears: a review. Bull NYU Hosp Jt Dis. 2006;64(3-4):114-8.

131. Palmer AK, Werner FW. The triangular fibrocartilage complex of the wrist — anatomy and function. J Hand Surg [Am]. 1981;6(2):153-62.

132. Sachar K. Ulnar-sided wrist pain: evaluation and treatment of triangular fibrocartilage complex tears, ulnocarpal impaction syndrome, and lunotriquetral ligament tears. J Hand Surg [Am]. 2008;33(9):1669-79.

133. Cooney WP, Linscheid RL, Dobyns JH. Triangular fibrocartilage tears. J Hand Surg [Am]. 1994;19(1):143-54.

134. Hermansdorfer JD, Kleinman WB. Management of chronic peripheral tears of the triangular fibrocartilage complex. J Hand Surg [Am]. 1991;16(2):340-6.

135. Trumble TE, Gilbert M, Vedder N. Ulnar shortening combined with arthroscopic repairs in the delayed management of triangular fibrocartilage complex tears. J Hand Surg [Am]. 1997;22(5): 807-13.

136. Shih JT, Lee HM, Tan CM. Early isolated triangular fibrocartilage complex tears: management by arthroscopic repair. J Trauma. 2002;53(5):922-7.

137. Feldon P, Terrono AL, Belsky MR. Wafer distal ulna resection for triangular fibrocartilage tears and/or ulna impaction syndrome. J Hand Surg [Am]. 1992;17(4):731-7.

138. Tomaino MM, Weiser RW. Combined arthroscopic TFCC debridement and wafer resection of the distal ulna in wrists with triangular fibrocartilage complex tears and positive ulnar variance. J Hand Surg [Am]. 2001;26(6):1047-52.

139. Minami A, Kato $\mathrm{H}$. Ulnar shortening for triangular fibrocartilage complex tears associated with ulnar positive variance. J Hand Surg [Am]. 1998;23(5):904-8.

140. Constantine KJ, Tomaino MM, Herndon JH, Sotereanos DG. Comparison of ulnar shortening osteotomy and the wafer resection procedure as treatment for ulnar impaction syndrome. J Hand Surg [Am]. 2000;25(1):55-60.

141. Bowers WH. Distal radioulnar joint arthroplasty: the hemiresectioninterposition technique. J Hand Surg [Am]. 1985;10(2):169-78.

142. Bickel KD. Arthroscopic treatment of ulnar impaction syndrome. J Hand Surg [Am]. 2008;33(8):1420-3.

143. Reagan DS, Linscheid RL, Dobyns JH. Lunotriquetral sprains. J Hand Surg [Am]. 1984;9(4):502-14.

144. Weiss AP, Sachar K, Glowacki KA. Arthroscopic debridement alone for intercarpal ligament tears. J Hand Surg [Am]. 1997;22 (2):344-9.

145. Shin AY, Weinstein LP, Berger RA, Bishop AT. Treatment of isolated injuries of the lunotriquetral ligament. A comparison of arthrodesis, ligament reconstruction and ligament repair. J Bone Joint Surg Br. 2001;83(7):1023-8. 
146. Viegas SF, Patterson RM, Peterson PD, Pogue DJ, Jenkins DK, Sweo TD, et al. Ulnar-sided perilunate instability: an anatomic and biomechanic study. J Hand Surg [Am]. 1990;15(2):268-78.

147. Trumble T, Bour CJ, Smith RJ, Edwards GS. Intercarpal arthrodesis for static and dynamic volar intercalated segment instability. J Hand Surg [Am]. 1988;13(3):384-90.

148. Buterbaugh GA, Palmer AK. Fractures and dislocations of the distal radioulnar joint. Hand Clin. 1988;4(3):361-75.

149. Adams BD, Berger RA. An anatomic reconstruction of the distal radioulnar ligaments for posttraumatic distal radioulnar joint instability. J Hand Surg [Am]. 2002;27(2):243-51.
150. Watson HK, Ryu JY, Burgess RC. Matched distal ulnar resection. J Hand Surg [Am]. 1986;11(6):812-7.

151. Lee JC, Healy JC. Normal sonographic anatomy of the wrist and hand. Radiographics 2005;25:1577-90.

152. Green DP, Hotchkiss RN, Pederson WC, Wolfe SW, editors. Green's operative hand surgery. Philadelphia: Elsevier; 2005.

153. Trumble T, Cornwall R, Budoff J. Core knowledge in orthopaedics: hand, elbow, and shoulder. Philadelphia: Mosby; 2006.

154. Chidgey LK. The distal radioulnar joint: problems and solutions. J Am Acad Orthop Surg 1995;3:95-109. 